\title{
The effect of charge mutations on the stability and aggregation of a human single chain Fv fragment
}

DOI:

10.1016/j.ejpb.2017.01.019

\section{Document Version}

Final published version

Link to publication record in Manchester Research Explorer

\section{Citation for published version (APA):}

Austerberry, J., Dajani, R., Panova, S., Roberts, D., Golovanov, A., Pluen, A., van der Walle, C. F., Uddin, S., Derrick, J., Warwicker, J., \& Curtis, R. (2017). The effect of charge mutations on the stability and aggregation of a human single chain Fv fragment. European Journal of Pharmaceutics and Biopharmaceutics, 115, 18-30. https://doi.org/10.1016/j.ejpb.2017.01.019

Published in:

European Journal of Pharmaceutics and Biopharmaceutics

\section{Citing this paper}

Please note that where the full-text provided on Manchester Research Explorer is the Author Accepted Manuscript or Proof version this may differ from the final Published version. If citing, it is advised that you check and use the publisher's definitive version.

\section{General rights}

Copyright and moral rights for the publications made accessible in the Research Explorer are retained by the authors and/or other copyright owners and it is a condition of accessing publications that users recognise and abide by the legal requirements associated with these rights.

\section{Takedown policy}

If you believe that this document breaches copyright please refer to the University of Manchester's Takedown Procedures [http://man.ac.uk/04Y6Bo] or contact uml.scholarlycommunications@manchester.ac.uk providing relevant details, so we can investigate your claim.

\section{OPEN ACCESS}


Research paper

\title{
The effect of charge mutations on the stability and aggregation of a human single chain Fv fragment
}

\author{
James I. Austerberry ${ }^{\mathrm{a}}$, Rana Dajani ${ }^{\mathrm{a}}$, Stanislava Panova ${ }^{\mathrm{b}}$, Dorota Roberts ${ }^{\mathrm{c}, 1}$, Alexander P. Golovanov ${ }^{\mathrm{d}}$, \\ Alain Pluen ${ }^{\mathrm{e}}$, Christopher F. van der Walle ${ }^{\mathrm{f}}$, Shahid Uddin ${ }^{\mathrm{f}}$, Jim Warwicker ${ }^{\mathrm{d}}$, Jeremy P. Derrick ${ }^{\mathrm{a}}$, \\ Robin Curtis ${ }^{\text {g,* }}$
}

\footnotetext{
${ }^{a}$ Faculty of Biology, Medicine and Health, University of Manchester, Manchester M13 9PT, United Kingdom

${ }^{\mathrm{b}}$ Faculty of Science and Engineering, University of Manchester, Manchester M1 7DN, United Kingdom

${ }^{\mathrm{c}}$ Drug Product Services, Lonza, Basel 4002, Switzerland

${ }^{\mathrm{d}}$ School of Chemistry, University of Manchester, Manchester M1 7DN, United Kingdom

e Manchester Pharmacy School, University of Manchester, M13 9PL, United Kingdom

${ }^{\mathrm{f}}$ Forumulation Sciences, MedImmune Ltd, Granta Park, Cambridge CB21 6GH, United Kingdom

${ }^{\mathrm{g}}$ School of Chemical Engineering and Analytical Science, University of Manchester, M1 7DN, United Kingdom
}

\section{A R T I C L E I N F O}

\section{Article history:}

Received 23 September 2016

Revised 14 January 2017

Accepted in revised form 15 January 2017

Available online 1 February 2017

\section{Keywords:}

ScFv

Protein-protein interactions

Aggregation

Protein stability

Charged mutations

\begin{abstract}
A B S T R A C T
The aggregation propensities for a series of single-chain variable fragment ( $\mathrm{scFv}$ ) mutant proteins containing supercharged sequences, salt bridges and lysine/arginine-enriched motifs were characterised as a function of $\mathrm{pH}$ and ionic strength to isolate the electrostatic contributions. Recent improvements in aggregation predictors rely on using knowledge of native-state protein-protein interactions. Consistent with previous findings, electrostatic contributions to native protein-protein interactions correlate with aggregate growth pathway and rates. However, strong reversible self-association observed for selected mutants under native conditions did not correlate with aggregate growth, indicating 'sticky' surfaces that are exposed in the native monomeric state are inaccessible when aggregates grow. We find that even though similar native-state protein-protein interactions occur for the arginine and lysine-enriched mutants, aggregation propensity is increased for the former and decreased for the latter, providing evidence that lysine suppresses interactions between partially folded states under these conditions. The supercharged mutants follow the behaviour observed for basic proteins under acidic conditions; where excess net charge decreases conformational stability and increases nucleation rates, but conversely reduces aggregate growth rates due to increased intermolecular electrostatic repulsion. The results highlight the limitations of using conformational stability and native-state protein-protein interactions as predictors for aggregation propensity and provide guidance on how to engineer stabilizing charged mutations.
\end{abstract}

(c) 2017 Published by Elsevier B.V. This is an open access article under the CC BY license (http://creativecommons.org/licenses/by/4.0/).

\section{Introduction}

Biopharmaceuticals are an important part of the drug portfolio of most major pharmaceutical companies. Biologic drug candidates are used to treat metabolic, cardiovascular, cancer, autoimmune and infectious diseases, amongst others. Proteinaceous products include peptides, enzymes, monoclonal antibodies (mAbs), antibody-like proteins and other scaffolds and fusions [91,92]; all of which may suffer physical and chemical instability. Broadly,

\footnotetext{
* Corresponding author at: Manchester Institute of Biotechnology, The University of Manchester, 131 Princess Street, Manchester M1 7DN, United Kingdom.

E-mail address: r.curtis@manchester.ac.uk (R. Curtis).

1 Current affiliation.
}

physical instability involves adsorption, unfolding and aggregation, all of which may occur cooperatively rather than in isolation [86]. The long term loss of monomer is generally predicted through quantitative monitoring of aggregation under accelerated and stress conditions over weeks to months. Recent progress has been made in: (i) the development of detailed kinetic models $[2,4,5,34,42,49,60,96]$; (ii) correlating aggregation kinetics with protein structure and folding [11,15,16,32,35,52,53,54,67,88]; (iii) and with native-state protein-protein interaction measurements $[36,46,57,74,75,79,82]$.

Aggregation can be described through models incorporating nucleation and subsequent growth steps such as Lumry-Eyring nucleation polymerization models $[1,2,9,50,96]$. Nucleation generally refers to the steps prior to formation of the smallest net 
irreversible aggregate, which can include partial unfolding, reversible association of partially unfolded intermediates, and conformational rearrangements. Once formed, the aggregates can grow through different mechanisms such as via monomer addition (referred to as chain polymerization), by aggregate-aggregate coalescence or condensation, and possibly phase separation or precipitation. Predicting aggregation is not always possible due to the multitude of possible pathways and difficulties in isolating key partially folded intermediates and characterizing their intermolecular interactions [68,70,94,97].

Many mutational approaches for improving aggregation resistance rely on manipulating protein electrostatic properties through charged mutations. Aggregation resistance has been increased through the method of supercharging proteins by engineering in an excess number of acidic $[25,45,85]$ or basic residues [58] or alternatively protein net charge can be increased by covalently attaching charged amino acid tags [83,87]. Similarly, heat resistant antibody $\mathrm{V}_{\mathrm{H}}$ domains isolated from a combinatorial library of mutations generated by phage display generally had a disproportionate number of acidic groups [3,26,39]. These studies indicate that the controlling factor is the protein net charge. However other work, based on phage display [27] and rational mutagenesis $[25,65,47]$, indicates that the spatial location of charged mutations controls the protein stability. However, care must be taken when engineering in charged mutations. If the protein net charge is close to zero, an anisotropic charge distribution can cause protein self association [13,14,71,99], which has been correlated with increased aggregation propensity $[55,80]$. To avoid increasing protein charge anisotropy, charged mutations should carry the same sign as the net charge on the corresponding protein scaffold $[31,100]$. Deconvoluting between these competing charge effects has led to confusion over whether negatively charged mutations are more effective than positively charged mutations [44,89]. Further, solubilizing effects of charged mutations are also specific to the chemical nature of the residue concerned. An increased abundance of lysine over arginine has been correlated with higher protein solubility through an informatics analysis [95].

Improving upon rational mutational strategies requires a better understanding of how the changes impact on the rate determining steps in aggregation pathways. Most rational design strategies such as Rosetta choose mutations that minimize the free energy of the native state to avoid increasing the formation of aggregation-prone partially folded or unfolded states [25,58]. The more challenging problem is identifying partially-folded regions on a protein that expose hot spots buried in nucleation or aggregate growth steps. A recently developed approach, the spatial aggregation predictor (SAP) identifies aggregation prone segments as hydrophobic regions with high dynamic exposure $[17,18]$. Whether or not SAP accurately predicts aggregation prone regions is not known since only aggregation rate data has been predicted, rather than the actual location of known aggregation hot spots. Indeed very limited experimental data exists for aggregation hot spots due to difficulties in identifying the key intermediate in aggregation pathways [69].

Further insight to the association steps in aggregation pathways can be gained by rationalizing why aggregation is correlated, in some instances, with native-state protein-protein interactions. For instance, recent work has established a strong correlation between the electrostatic contribution to native protein-protein interactions and the type of aggregate growth pathways as well as aggregate growth rates $[9,43,63,71,75]$. Electrostatic interactions correlate with aggregate growth because charged groups remain exposed in the native state and on growing aggregates. Conversely, it is not clear whether surfaces exposed on nativelyfolded proteins are buried during aggregate growth and nucleation. One distinct possibility is that hot spots exposed by partially folded regions of the protein are buried in the nucleation step, while aggregate growth occurs at least in part by burying native surfaces.

In this work, the effect of mutations on the aggregation properties of a recombinant human single-chain variable fragment (scFv) [28] was studied. Mutants with surface patches of positive or negative charge, with engineered salt bridges, and with lysine/arginine swaps in corresponding sequence-rich regions were generated. Experiments were carried out at low and moderate ionic strength and for two $\mathrm{pH}$ values to delineate the effects of electrostatic interactions. Thermally-accelerated aggregation studies were complemented with measurements of native protein-protein interactions obtained from dynamic light scattering (DLS), and with measurements of conformational stability quantified from equilibrium chemical denaturation and differential scanning fluorimetry measurements. The main aims of the study were first to further elucidate the relationship between steps in aggregation pathways and native-state protein-protein interactions and secondly to understand better the molecular basis for how mutations alter aggregation behaviour.

\section{Materials and methods}

\subsection{Mutant design}

Modelling of the surface properties for the scFv variants was performed with a comparative model generated from the closest available Protein Data Bank structure (www.rcsb.org; 2GHW:B), using the pairwise sequence alignment and a procedure to optimise side-chain placement [20]. A depiction of the wild type polarity surface distribution is given in Fig. $1 \mathrm{~A}$, where red and blue correspond to non-polar and polar regions, respectively. A large non-polar region on the solvent exposed surface was identified for introducing mutations and generating variants (all sequences are shown in Supplementary Information (SI) Fig. S1). Over-
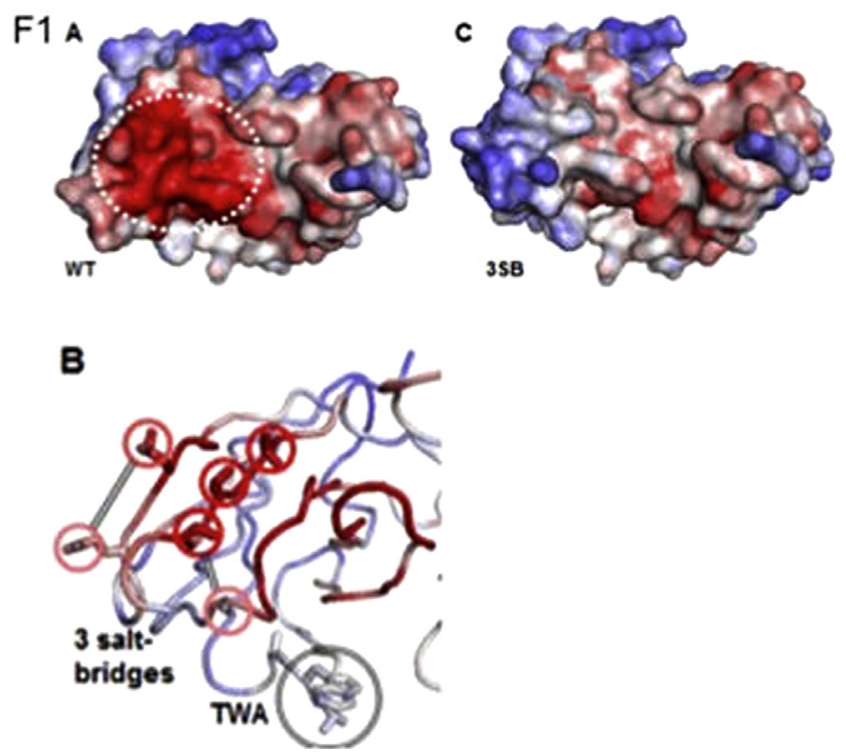

Fig. 1. (A) The molecular surface of modelled scFv is colour-coded according to polarity, with red denoting most non-polar, blue most polar, and white intermediate. This calculation is patch based, leading to the smooth transition between regions. The largest non-polar red-patch is highlighted for wild-type scFv. (B) The colour-coding of panel $(\mathrm{A})$ is maintained in this focus on the region immediately surrounding the non-polar patch. Framework scFv is shown, with sidechains for the 6 residues that are mutated to form the 3SB mutant, and the TWA segment (which is mutated to DSV). Modelled pairings for the introduced salt-bridges are shown. (C) The equivalent surface to panel A is shown, but for the 3SB mutant, showing ablation of the non-polar patch. (For interpretation of the references to colour in this figure legend, the reader is referred to the web version of this article.) 
charged mutants were generated by placing into the hydrophobic patch either five lysine residues (5K), five arginine residues (5R), or five glutamic acid residues (5E). A hydrophobic TWA sequence was replaced with DSV, which is a common replacement sequence found in other scFvs, including the 2GHW:B template [37]. Pairs of lysine and glutamic acid residues were introduced to create mutants with one, two, or three salt bridges, labelled as 1SB, 2SB, or $3 \mathrm{SB}$, respectively. The surface locations for the three proposed salt bridges and the mutated TWA sequence are shown in Fig. 1B. Fig. 1C depicting an updated surface polarity distribution for 3SB shows how the three salt bridges reduce the non-polar surface area. Mutants were also created in which 4 lysine residues were substituted for 4 arginine residues (4RK) or 7 arginine residues were substituted for 7 lysine residues (7KR), with the sites being located more extensively over the protein surface.

\subsection{Calculation of protein surface properties}

The surface polarity of the modelled scFv was calculated with a patch-based scheme [95] in which each surface patch was evaluated as a ratio of non-polar to polar atom surface area; this property was included in the B-factor field of a standard coordinate file to allow plotting with a colour ramp (Fig. 1A). The theoretical net charge for each protein shown in Table 1 was calculated from its amino acid sequence, using analysis software written for a previous study [95].

\subsection{Protein production}

The scFv gene [28] was cloned into the pET22b vector (Novagen) using the NdeI/Xhol restriction sites (New England Biolabs). The protein sequence is shown in the supplementary information. All mutants were generated using ThermoFisher GeneArt, with codon usage optimised for E. coli, except DSV and 1SB which were generated by site directed mutagenesis using Q5 high fidelity DNA polymerase (New England Biolabs) according to manufacturer's instructions. Forward and reverse primers for these are presented in the supplementary information. The scFv-pET22b vector was transformed into T7 Shuffle Express cells (New England Biolabs) and a single colony grown in $50 \mathrm{~mL} 2 \mathrm{xYT}$ media (Formedium) containing $100 \mu \mathrm{g} / \mathrm{mL}$ ampicillin (Sigma) at $30^{\circ} \mathrm{C}$ for $4 \mathrm{~h}$, then transferred to $600 \mathrm{~mL}$ flasks of the same media with a starting OD of 0.075 and grown to an OD of 0.8 before induction with IPTG (Generon) to a concentration of $0.25 \mathrm{mM}$ and incubated overnight at $16{ }^{\circ} \mathrm{C}$. After pelleting at $10,000 \mathrm{~g}$ for $20 \mathrm{~min}, 10 \mathrm{~g}$ of cells were resuspended in $50 \mathrm{~mL} 50 \mathrm{mM}$ Tris $25 \mathrm{mM} \mathrm{NaCl} \mathrm{pH} 8.5$ (pH 7.5 for $5 \mathrm{~K}, 5 \mathrm{R}$ and 5E) with $50 \mu$ l DNase and $1 \times$ Complete protease inhibitor tablet (Roche Applied Science) and lysed by sonication for $5 \mathrm{~min}$ with the cellular debris removed by centrifugation at $15,000 \mathrm{~g}$ for $30 \mathrm{~min}$ and supernatant filtered through a $0.4 \mu \mathrm{m}$ filter (Millipore). Samples were loaded onto a $25 \mathrm{~mL}$ protein A Sepharose column (Sigma), washed with $25 \mathrm{mM}$ TRIS $25 \mathrm{mM} \mathrm{NaCl} \mathrm{pH} 7.5$ and eluted with $100 \mathrm{mM}$ pH 3.5 citrate buffer. 1.5 M TRIS was used to $\mathrm{pH}$ the eluent to $\mathrm{pH} 7$, and the proteins were dialysed into $20 \mathrm{mM} \mathrm{NaPO} 4150 \mathrm{mM}$ $\mathrm{NaCl} \mathrm{pH} 6.9$ (pH 7.5 for $5 \mathrm{~K}$ and $5 \mathrm{R}, \mathrm{pH} 8$ for DSV and $\mathrm{pH} 7$ for $5 \mathrm{E}$ ). The protein was concentrated and loaded onto a Superdex HiLoad 16/600 S 75 column (GE Healthcare) and the monomer fraction collected and verified by mass spectrometry. The eluted samples at a protein concentration of $10 \mathrm{~g} / \mathrm{L}$ were then frozen at $-80^{\circ} \mathrm{C}$ until further use.

\subsection{Buffers}

All experiments have been carried out using either a $\mathrm{pH} 5$ buffer containing sodium acetate at an ionic strength of $25 \mathrm{mM}$ (containing $39.3 \mathrm{mM}$ acetate ion) or a $\mathrm{pH} 7$ buffer containing sodium phosphate at an ionic strength of $25 \mathrm{mM}$ (containing $11.6 \mathrm{mM}$ phosphate ion). Varying amounts of sodium chloride have been added to the buffers.

\subsection{Sample preparation}

Before each measurement, $0.5 \mathrm{~mL}$ of a protein sample was prepared by dialyzing two times against $1 \mathrm{~L}$ of the appropriate buffer using GeBAflex-Midi Dialysis tubes (3.5 kDa MWCO). A vacuum filtration unit with Millipore $0.2 \mu \mathrm{m}$ membrane was used to remove dust from all dialysis buffers. The first and second dialysis runs were carried out for two hours and overnight, respectively. After dialysis, the sample was always filtered through a $0.02 \mu \mathrm{m}$ syringe top filter (Whatman). Protein samples were diluted to the desired concentration using the second dialysis buffer.

\subsection{Circular dichroism}

Experiments were undertaken on the Chirascan spectrophotometer (Applied Photophysics). Protein solutions of $50 \mu$ l volume at $1 \mathrm{~g} / \mathrm{L}$ were placed in $1 \mathrm{~mm}$ pathlength quartz Hellma cell with Peltier temperature controlled stage at $25^{\circ} \mathrm{C}$. Spectra were recorded at $190-260 \mathrm{~nm}$ with an acquisition time of $5 \mathrm{~s}$ at $0.5 \mathrm{~nm}$ increments and normalised by subtraction with a corresponding buffer blank.

\subsection{Dynamic light scattering (DLS)}

The diffusion coefficient and radius of hydration of each sample was determined using the Wyatt Dynapro system and DYAMICS software, using the laser wavelength of $830 \mathrm{~nm}$ with a scattering angle of $158^{\circ} .30 \mu \mathrm{l}$ sample volume was used in 384 well plates (Nalge NUNC international) and capped with silicon oil. Acquisition time was set at $5 \mathrm{~s}$ and 10 collections taken of each, with each sample run in triplicate. Correlation functions were determined by the

Table 1

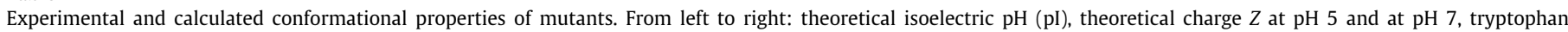

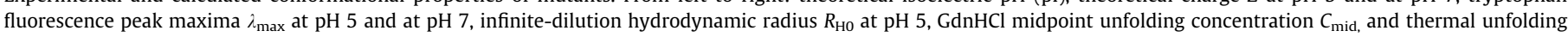
temperature $T_{\mathrm{DSF}}$.

\begin{tabular}{|c|c|c|c|c|c|c|c|c|}
\hline Mutant & $\mathrm{pI}$ & $Z(e) \mathrm{pH} 5$ & $Z(e) \mathrm{pH} 7$ & $\lambda_{\max }(\mathrm{nm}) \mathrm{pH} 5$ & $\lambda_{\max }(\mathrm{nm}) \mathrm{pH} 7$ & $R_{\mathrm{Ho}}(\mathrm{nm})$ & $C_{\text {mid }}(\mathrm{M})$ & $T_{\mathrm{DSF}}\left({ }^{\circ} \mathrm{C}\right)$ \\
\hline WT & 7.8 & 5.62 & 1.35 & $334.6 \pm 0.1$ & $335.6 \pm 0.1$ & $2.41 \pm 0.01$ & $1.49 \pm 0.04$ & $44.9 \pm 0.5$ \\
\hline DSV & 6.9 & 4.71 & 0.35 & $333.4 \pm 0.3$ & $335.6 \pm 0.1$ & $2.35 \pm 0.01$ & $1.78 \pm 0.06$ & $46.0 \pm 0.2$ \\
\hline $5 \mathrm{~K}$ & 9.0 & 10.60 & 6.35 & $334.6 \pm 0.1$ & $336.6 \pm 0.5$ & $2.39 \pm 0.01$ & $1.25 \pm 0.08$ & $38.5 \pm 0.1$ \\
\hline $5 E$ & 5.3 & 1.62 & -3.64 & $334.6 \pm 0.1$ & $335.6 \pm 0.1$ & $2.60 \pm 0.02$ & $1.25 \pm 0.11$ & $43.3 \pm 0.7$ \\
\hline $5 R$ & 9.0 & 10.62 & 6.35 & $334.6 \pm 0.1$ & $335.1 \pm 0.3$ & $2.52 \pm 0.04$ & $1.27 \pm 0.10$ & $37.2 \pm 0.1$ \\
\hline $3 S B$ & 7.8 & 6.22 & 1.35 & $334.1 \pm 0.1$ & $335.6 \pm 0.1$ & $2.40 \pm 0.01$ & $1.47 \pm 0.06$ & $46.6 \pm 2.3$ \\
\hline $2 \mathrm{SB}$ & 7.8 & 6.02 & 1.35 & $334.6 \pm 0.1$ & $335.6 \pm 0.1$ & $2.39 \pm 0.01$ & $1.51 \pm 0.03$ & $46.3 \pm 1.0$ \\
\hline $1 \mathrm{SB}$ & 7.8 & 5.82 & 1.35 & $334.9 \pm 0.2$ & $335.6 \pm 0.1$ & $2.40 \pm 0.01$ & $1.30 \pm 0.08$ & $46.6 \pm 0.7$ \\
\hline 7KR & 7.8 & 6.62 & 2.35 & $334.5 \pm 0.1$ & $335.6 \pm 0.1$ & $2.37 \pm 0.01$ & $1.55 \pm 0.04$ & $46.1 \pm 0.5$ \\
\hline $4 \mathrm{RK}$ & 7.8 & 5.62 & 1.35 & $335.2 \pm 0.1$ & $335.6 \pm 0.1$ & $2.43 \pm 0.01$ & $1.25 \pm 0.09$ & $46.4 \pm 0.5$ \\
\hline
\end{tabular}


DYNAMICS software. Fits to the correlation function were performed between 1.5 and $6 \times 10^{4} \mu \mathrm{s}$, using a cumulant analysis and a regularization analysis as implemented in the DYNAMICS software. The regularisation fitting uses the Dynals algorithm from Alango, Ltd [33]. The cumulant analysis was used to determine the $z$-average diffusion coefficient $D$ and the polydispersity $P_{\mathrm{d}}$ defined as the width of the diffusion coefficient normalized by $D$.

Measurements were carried out at 5, 10, 15 and $20^{\circ} \mathrm{C}$, and then in further $1^{\circ} \mathrm{C}$ increments. The sample chamber was purged with nitrogen at 8 bar in conditions below $15^{\circ} \mathrm{C}$ to negate water vapour condensation in the instrument. Each temperature programme experiment included 18 samples with 6 different protein concentrations ranging between 0.5 and $10 \mathrm{~g} / \mathrm{L}$ measured in triplicate. A typical temperature scan took $35 \mathrm{~min}$ including $1 \mathrm{~min}$ to allow for temperature equilibration.

The measurements at temperatures of $25^{\circ} \mathrm{C}$ and below were used to determine the interaction parameter $k_{\mathrm{D}}$ and infinite dilution protein hydrodynamic radius $R_{\mathrm{H}, 0}$. The diffusion coefficient $D$ calculated using the cumulant analysis can be used to calculate $k_{\mathrm{D}}$

$D=D_{0}\left[1+k_{D} c\right]$

where $D_{0}$ is the infinite dilution of the diffusion coefficient. $R_{\mathrm{H}, 0}$ was calculated using the Stokes-Einstein relation

$R_{H, 0}=\frac{k_{B} T}{6 \pi \mu D_{0}}$

where $\mu$ is solvent viscosity, $T$ is temperature, and $k_{\mathrm{B}}$ is Boltzmann's constant.

\subsection{Temperature ramped static light scattering (SLS)}

An Optim 1000 instrument (Unchained Labs) was used to record static light scattering signals during a temperature ramp using laser excited light at a wavelength of $473 \mathrm{~nm}$. Changes in light scattering intensity reflect changes in the weight average molecular weight due to aggregation. $9 \mu \mathrm{l}$ samples at a protein concentration of $1 \mathrm{~g} / \mathrm{L}$ were heated in $0.5^{\circ} \mathrm{C}$ increments from 25 to $80^{\circ} \mathrm{C}$. The heating rate between temperature intervals was set to $1^{\circ} \mathrm{C} / \mathrm{min}$. A typical temperature scan of 48 samples took two and a half minutes including $30 \mathrm{~s}$ for thermal equilibration. All measurements were done in duplicate.

The temperature dependent light scattering profiles were fit to a two-parameter empirical equation given by

$\frac{\mathrm{d} I}{\mathrm{~d} T}=\exp \left[-E_{\mathrm{a}}\left(\frac{1}{T}-\frac{1}{T_{\mathrm{SLS}}}\right)\right]$

where $I$ is absolute light scattering intensity, $T$ is temperature, and $T_{\mathrm{SLS}}$ and $E_{\mathrm{a}}$ are fitting parameters. Eq. (3) provided an accurate fit to the data over a temperature range when the light scattering signal remained below 35,000 kcps. This range was used in all the fitting unless otherwise noted. The fitting was carried out using the leastsq minimization routine of a python script.

\subsection{Extrinsic fluorescence}

Temperature-ramp fluorescence measurements were carried in the Optim 1000 instrument. The SYPRO ${ }^{\circledR}$ orange dye was supplied in DMSO at 100 times the recommended working concentration and added to each sample with protein concentration of $1 \mathrm{~g} / \mathrm{L}$ immediately prior to loading into the $9 \mu \mathrm{l}$ sample cuvette. The Optim 1000 uses a $473 \mathrm{~nm}$ laser for excitation and records the fluorescence emission spectrum at wavelengths between 500 and $700 \mathrm{~nm}$. The temperature programme from the static light scattering experiment was followed.
The lowest unfolding temperature $T_{\mathrm{DSF}}$ was determined from fitting the fluorescence intensity as a function of temperature to the Boltzmann Equation [62], which assumes a two-state unfolding transition. The $T_{\mathrm{DSF}}$ value corresponds to the mid-point or inflection point of the transition. The fitting was carried out using a python script and the leastsq algorithm.

\subsection{Gdn HCl unfolding}

A Cary Eclipse fluorescence spectrophotometer (Agilent) was used to carry out chemical equilibrium denaturation experiments on proteins samples at a concentration of $1 \mathrm{~g} / \mathrm{L}$. The instrument uses an excitation wavelength of $290 \mathrm{~nm}$ with a $2.5 \mathrm{~mm}$ slit width, and emission at $335 \mathrm{~nm}$ with a $5 \mathrm{~mm}$ slit width. Decreasing concentrations of $\mathrm{GdnHCl}$ were used from $6 \mathrm{M}$ to $3 \mathrm{M}$ in $1 \mathrm{M}$ steps and 2.5 to $0 \mathrm{M}$ in $0.1 \mathrm{M}$ decrements. Samples were allowed to equilibrate for $1 \mathrm{~min}$ before acquisition, with three readings taken to ensure the sample was in equilibrium.

\subsection{NMR}

Protein samples for nuclear magnetic resonance (NMR) experiments were prepared in $25 \mathrm{mM}$ acetate buffer $\mathrm{pH} 5$ with addition of $5 \%$ D2O. ${ }^{1} \mathrm{H}$ NMR experiments were performed on a Bruker Avance 800-MHZ spectrometer equipped with cryoprobe. We used the standard Bruker Topspin 3.1 pulse sequence zgesgp. For all constructs spectra were recorded at increasing temperatures from 5 to $70{ }^{\circ} \mathrm{C}$ in $5{ }^{\circ} \mathrm{C}$ increments. The sample was kept for $180 \mathrm{~s}$ at each given temperature before starting the experiment. Chemical shifts were referenced according to the water chemical shift dependence on temperature. Signals were integrated between -0.3 and $-1.7 \mathrm{ppm}$ which corresponds to the folded protein region. Integrated areas were normalised against the maximum integral value for each mutant and corrected for the change in dynamic viscosity of the buffer as a function of temperature.

\section{Results}

\subsection{Spectroscopic studies indicate mutations do not change native conformation}

The effect of mutation on protein conformation was assessed by using circular dichroism (CD) in solutions at pH 5 without sodium chloride. Spectra for all mutants and the wild type are shown in Fig. 2. The positions for the minima and maxima of all spectra vary by less than $1 \mathrm{~nm}$. The close agreement indicates a similar secondary structure for all mutants, with only a small difference observed in the CD spectra of the DSV mutant versus the wild type (WT). A similar fold between all the mutants was also confirmed from intrinsic fluorescence emission spectra data taken for samples at $\mathrm{pH} 5$ and at $\mathrm{pH}$ 7. The location of the emission maxima (listed in Table 1) for all mutants at $\mathrm{pH} 5$ are within $0.6 \mathrm{~nm}$ of the wild type position located at $334.6 \mathrm{~nm}$. A red-shift of ca. $\sim 1 \mathrm{~nm}$ in the peak maxima occurs with a pH shift from 5 to 7 indicating that the aromatic residues become less solvent-exposed [84] possibly because the protein fold is 'more compact' at $\mathrm{pH}$ 7. There is also very little variation of the peak position between all mutants at $\mathrm{pH} 7$.

\subsection{Overcharged mutants exhibit lower conformational stabilities}

The relative stabilities of the mutants were compared by monitoring intrinsic fluorescence as a function of guanidium hydrochloride concentration. A 2-state denaturation model, which assumes an equilibrium between folded and denatured forms, did not provide adequate agreement with the data. This is consistent 


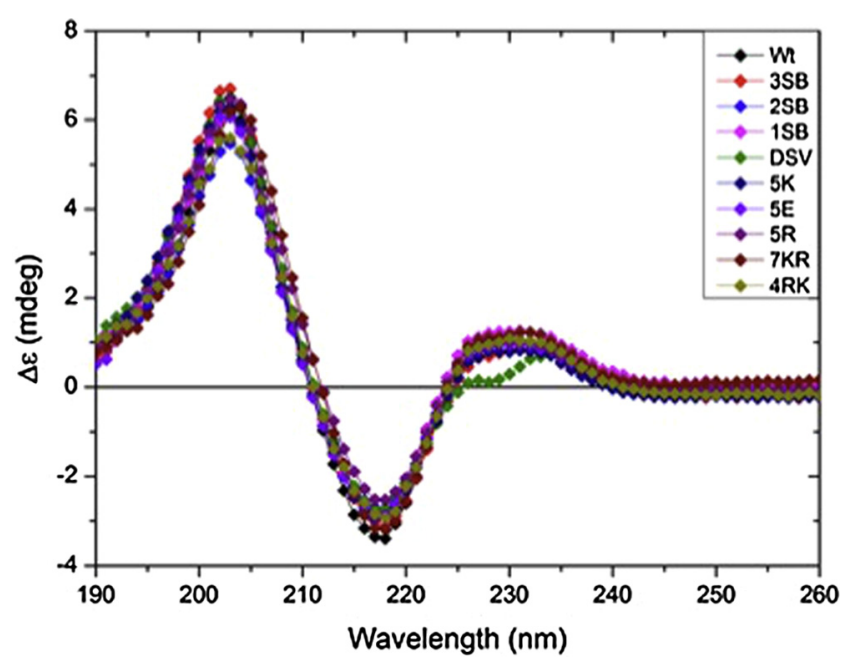

Fig. 2. Circular dichroism spectra between 260 and $190 \mathrm{~nm}$ for wild type (Wt) and each mutant at $\mathrm{pH} 5$.

with other studies on scFv proteins, which indicate multiple unfolding transitions [98]. The free energy of unfolding cannot therefore be determined from the fluorescence profiles; instead we report the denaturant concentration at the midpoint of the fluorescence change (referred to as $C_{\text {mid }}$ ) in Table 1 to provide a measure of the relative stabilities. A lower midpoint should reflect a lower conformational stability because less denaturant is required to unfold the protein. The mutants with the lowest midpoint concentrations correspond to the patch-charged mutants (5K, 5E, 5R) and the arginine-lysine swap mutant 4RK.

Differential scanning fluorimetry (DSF) data using the extrinsic fluorophore SYPRO ${ }^{\circledR}$ Orange was used to further characterise the thermal stability of the mutants. In a DSF experiment, the fluorescence spectrum of the dye molecule is monitored as a function of temperature. The fluorescence depends sensitively on the hydrophobic environment of the dye. In free solution, there is negligible fluorescence from the dye, while the fluorescence increases when the dye binds to hydrophobic regions of the protein that are exposed upon unfolding. The thermal unfolding temperature $\left(T_{\mathrm{DSF}}\right)$ corresponds to the temperature midpoint of the lowest temperature unfolding transition. The results of the measurements in solutions at pH 5 are tabulated in Table 1 . The $T_{\mathrm{DSF}}$ is equal to $45.0^{\circ} \mathrm{C}$ for the wild type protein. The basic mutants $5 \mathrm{R}$ and $5 \mathrm{~K}$ exhibit significantly lower thermal unfolding transitions ( $T_{\mathrm{DSF}}$ equal to 38.5 and $37.2^{\circ} \mathrm{C}$, respectively), while that of $5 \mathrm{E}$ is only slightly lower ( $T_{\mathrm{DSF}}$ equal to $43.3^{\circ} \mathrm{C}$ ). The thermal transitions for all other mutants are similar to or approximately $1^{\circ} \mathrm{C}$ greater than the wild type.

The mutants $5 \mathrm{~K}$ and $5 \mathrm{R}$ exhibit lower chemical and thermal stability than the wild type. The decrease in conformational stability is likely due to intra-molecular charge repulsion arising from the relative proximal locations of the mutated basic groups. A similar charge repulsion is also expected for the $5 \mathrm{E}$ mutant as theoretical calculations indicate the acidic groups should be fully deprotonated at $\mathrm{pH} 5$. The chemical stability of $5 \mathrm{E}$ is indeed similar to $5 \mathrm{~K}$ and $5 \mathrm{R}$, but the thermal stability is intermediate of $5 \mathrm{~K}$ or $5 \mathrm{R}$ and the wild type. Because mutations have been introduced on a positively charged template at $\mathrm{pH} 5$, the intramolecular charge repulsion is less for the negatively charged patch variant versus the positive variants, which might explain why $5 \mathrm{E}$ appears more stable than $5 \mathrm{~K}$ or $5 \mathrm{R}$.

In the Supplementary Information we provide results from differential scanning calorimetry of the wild type in solutions at $\mathrm{pH} 5$, which was also used to assess the thermal folding stability. The thermal scan shown in Fig. S2 indicates a large endothermic tran- sition at a temperature of $69.5^{\circ} \mathrm{C}$, but no peak is detected near the transition temperature expected from the DSF experiment $\left(T_{\mathrm{DSF}}\right.$ equal to $45.0^{\circ} \mathrm{C}$ for the wild type). The large difference in temperatures indicates multiple unfolding transitions. The large thermal signature of the high temperature transition indicates this corresponds to global unfolding, while the low temperature transition likely corresponds to unfolding of a localized region on the protein. The low temperature transition creates the aggregation prone states as aggregation of the wild type begins to occurs at $35^{\circ} \mathrm{C}$.

\subsection{Thermal ramped NMR provides relative measure of monomer loss}

NMR was used to provide insight into the temperature-ramped kinetic behaviour of the mutants in the pH 5 buffer. Estimates of monomer concentration can be determined from integrating the peak intensities obtained from a $1 \mathrm{D}^{1} \mathrm{H}$ NMR scan. Only monomers contribute to the ${ }^{1} \mathrm{H}$ NMR signal, as signals from aggregates over $100 \mathrm{kDa}$ broaden to the point where they are not detected [12]. Fig. 3 shows a plot of the normalized peak area with increasing temperature, in $5{ }^{\circ} \mathrm{C}$ increments between 20 and $70{ }^{\circ} \mathrm{C}$. The relative monomer-loss rates are reflected by $T_{\mathrm{NMR}}$ (shown in Table 2 ), which corresponds to the temperature where approximately one half of the protein is aggregated. Monomer loss occurs at the lowest temperatures for the over-charged mutants, while the wildtype, 4RK, and 7KR mutants exhibit the slowest monomer loss.

\subsection{Protein-protein interactions characterized in terms of $k_{D}$}

Characterizing native-state protein-protein interactions from diffusion coefficient measurements in terms of $k_{\mathrm{D}}$ values requires carrying out measurements on solutions without any detectable levels of aggregates. To check how the dynamic light scattering analysis changed with aggregate formation, we carried out extended isothermal runs for the wild type at temperatures of $29^{\circ} \mathrm{C}$ and $33^{\circ} \mathrm{C}$. At $29^{\circ} \mathrm{C}$, the radius of hydration $\left(R_{\mathrm{H}}\right)$ and the polydispersity $\left(P_{\mathrm{d}}\right)$ remained constant for a period of $3 \mathrm{~h}$. At $33^{\circ} \mathrm{C}$, after 10-30 min, the onset of aggregation was reflected by a gradual increase in $R_{\mathrm{H}}$ and a dramatic increase in the $P_{\mathrm{d}}$ from $10 \%$ to values much greater than $20 \%$, or in most cases a multimodal population formed. As such, we only report $k_{\mathrm{D}}$ values for conditions corresponding to a monomodal size population when $P_{\mathrm{d}}$ values remained constant on the time scale of the experiments $(\sim 3 \mathrm{~h})$. In most instances $P_{\mathrm{d}}$ values were less than $10 \%$, indicating a monodispersed sample. However, for a small number of samples noted below, we observed $P_{\mathrm{d}}$ values greater than $10 \%$ but less than $20 \%$, indicating the presence of small oligomers.

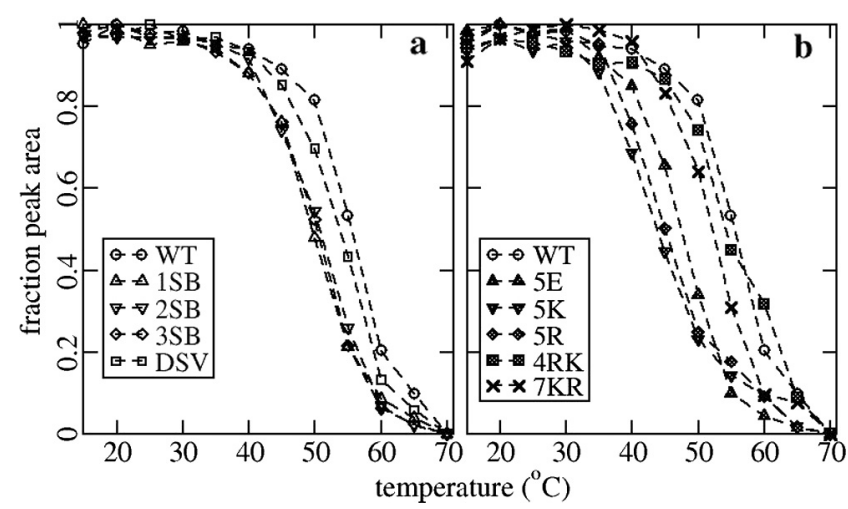

Fig. 3. Fractional integrated ${ }^{1} \mathrm{H}$ NMR peak intensities for samples at $\mathrm{pH} 5$ as a function of temperature for (a) WT, 1SB, 2SB, 3SB, and DSV and (b) WT, 4RK, 5E, 5K $5 \mathrm{R}$, and $7 \mathrm{KR}$. All spectra were taken at a protein concentration of $2.85 \mathrm{mg} / \mathrm{mL}$. Lines are drawn as a guide to the eye. 
Table 2

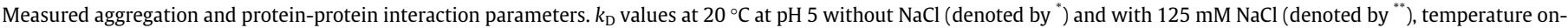
set of aggregation $T_{\mathrm{DLS}}$ at $\mathrm{pH} 5$ without $\mathrm{NaCl}$ (denoted by ${ }^{*}$ ) and with $125 \mathrm{mM} \mathrm{NaCl}$ (denoted by ${ }^{* *}$ ), temperature mid-point of monomer loss by NMR $T_{\mathrm{NMR}}$ at pH 5 .

\begin{tabular}{|c|c|c|c|c|c|}
\hline Mutant & $k_{\mathrm{D}}(\mathrm{mL} / \mathrm{g}) 20^{\circ} \mathrm{C}^{*}$ & $k_{\mathrm{D}}(\mathrm{mL} / \mathrm{g}) 20^{\circ} \mathrm{C}^{* *}$ & $T_{\mathrm{DLS}}\left({ }^{\circ} \mathrm{C}\right)^{*}$ & $T_{\mathrm{DLS}}\left({ }^{\circ} \mathrm{C}\right)^{* *}$ & $T_{\mathrm{NMR}}\left({ }^{\circ} \mathrm{C}\right)$ \\
\hline WT & $0.9 \pm 0.5$ & $-2.6 \pm 0.5$ & 37 & $26-28$ & $55.7 \pm 0.4$ \\
\hline DSV & $0.4 \pm 0.2$ & $-2.8 \pm 0.3$ & 36 & $25-26$ & $53.9 \pm 0.3$ \\
\hline $5 \mathrm{~K}$ & $11.4 \pm 1.9$ & $-13.0 \pm 2.5$ & 30 & $21-24$ & $44.2 \pm 0.5$ \\
\hline $5 \mathrm{E}$ & $-9.4 \pm 0.5$ & $-5.6 \pm 2.2$ & 29 & 22 & $47.5 \pm 0.2$ \\
\hline $5 \mathrm{R}$ & $-4.3 \pm 0.5$ & $-10.3 \pm 1.8$ & 30 & $26-29$ & $45.1 \pm 0.5$ \\
\hline $3 S B$ & $2.4 \pm 0.5$ & $-7.4 \pm 1.1$ & 36 & $23-26$ & $50.4 \pm 0.2$ \\
\hline $2 S B$ & $1.7 \pm 0.7$ & $-1.4 \pm 0.7$ & 36 & 28 & $50.8 \pm 0.3$ \\
\hline $1 \mathrm{SB}$ & $-0.5 \pm 0.6$ & $-5.0 \pm 1.3$ & 37 & $27-28$ & $50.0 \pm 0.4$ \\
\hline $7 \mathrm{KR}$ & $0.3 \pm 0.6$ & $-6.7 \pm 0.7$ & 35 & $23-26$ & $52.2 \pm 0.5$ \\
\hline 4RK & $2.3 \pm 1.3$ & $-3.6 \pm 1.6$ & $>43$ & 31 & $56.4 \pm 0.9$ \\
\hline
\end{tabular}

Table 1 shows the infinite-dilution hydrodynamic radius $R_{\mathrm{H}, 0}$ of each mutant measured at $20^{\circ} \mathrm{C}$ in the $\mathrm{pH} 5$ buffer. Each mutant has a similar size to the wild type equal to $2.41 \mathrm{~nm}$ providing additional support that mutations have not impacted protein conformation. The exceptions are two of the charged mutants $5 \mathrm{E}$ and $5 \mathrm{R}$ with increased radii of 2.60 and $2.52 \mathrm{~nm}$ respectively. The slight increase in size may be due to partial protein expansion near the highly charged patch introduced by the mutations.

$k_{\mathrm{D}}$ values are shown for each of the mutants in solutions at $\mathrm{pH} 5$ without any added salt in Fig. 4a and b, and with $125 \mathrm{mM}$ sodium chloride in Fig. $4 \mathrm{c}$ and d. Values taken at $20^{\circ} \mathrm{C}$ are also tabulated in Table 2 . Increasingly positive values of $k_{\mathrm{D}}$ reflect stronger net protein-protein repulsion, while increasingly negative values correspond to enhancing attractive protein-protein interactions. Protein-protein interactions are insensitive to temperature, except for a noticeable increase in repulsion for all mutants at $5{ }^{\circ} \mathrm{C}$.

Changes to the values of $k_{\mathrm{D}}$ with increasing ionic strength can be rationalized in terms of electrostatic interactions using the double layer force derived from Derjaguin-Landau-Verwey-Overbeek (DLVO) theory $[6,59,71]$. The double-layer force is given by a repulsive Yukawa potential that has a magnitude proportional to the protein net charge squared and follows an exponential decay with a range given by the Debye length (equal to the inverse of the Debye-Huckel parameter $\kappa$ ). Using the repulsive Yukawa potential, the calculated decrease in $k_{\mathrm{D}}$ when increasing sodium chloride concentration from 0 to $125 \mathrm{mM}$ is $3.0 \mathrm{~mL} / \mathrm{g}$ and $4.7 \mathrm{~mL} / \mathrm{g}$ for a theoretical protein charge equal to $5 e$ and $6 e$, respectively. The calculated change is in good agreement with the measured values of $k_{\mathrm{D}}$

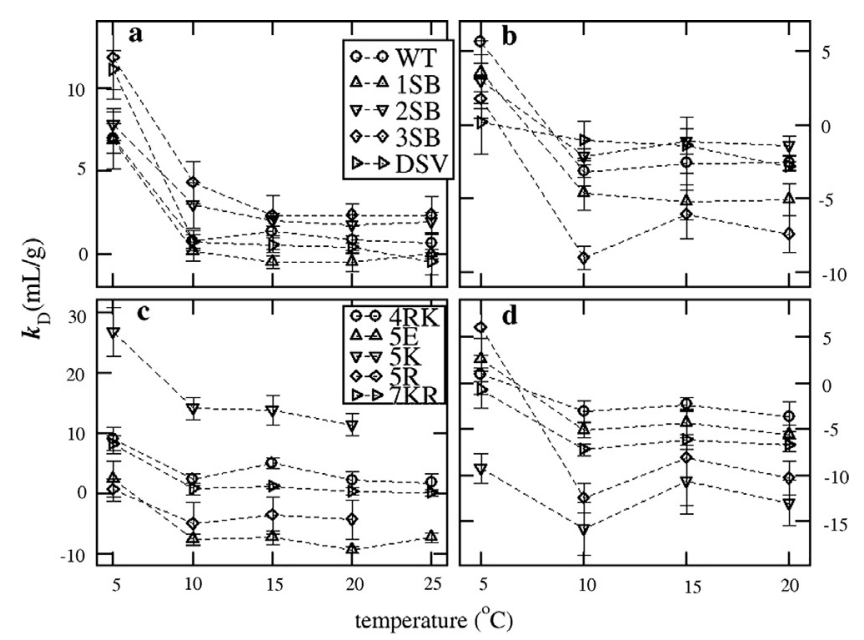

Fig. 4. $k_{\mathrm{D}}$ values measured as a function of temperature in $\mathrm{pH} 5$ solutions for WT, 1SB, 2SB, 3SB, DSV (a) without added sodium chloride, and (b) with $125 \mathrm{mM}$ sodium chloride, and for 5R, 5E, 5K, 4RK, 7KR (c) without added sodium chloride, and (d) with $125 \mathrm{mM}$ sodium chloride. Lines are drawn as a guide to the eye. for 4RK, wild type, 1SB, 2SB and DSV proteins (see Table 2 for corresponding $k_{\mathrm{D}}$ values). There is a much larger drop in the $k_{\mathrm{D}}$ value for $3 \mathrm{SB}$ equal to $10 \mathrm{~mL} / \mathrm{g}$ reflecting a stronger salt-induced selfassociation through an unknown mechanism.

The effect of charged mutations on the protein-protein interactions for the $5 \mathrm{~K}$ mutant was manifested by a much larger $k_{\mathrm{D}}$ value when compared against the wild-type for the solutions without added salt $(11.4 \mathrm{~mL} / \mathrm{g}$ for $5 \mathrm{~K}$ versus $0.9 \mathrm{~mL} / \mathrm{g}$ for wild-type). A much larger electrostatic repulsion is due to the increase in net charge of $5 \mathrm{~K}$. A similar enhancement in protein-protein repulsion is expected for $5 R$. Interestingly, protein-protein interactions for $5 \mathrm{R}\left(k_{\mathrm{D}}\right.$ equal to $\left.-4.3 \mathrm{~mL} / \mathrm{g}\right)$ are more attractive than for the wildtype appearing to indicate the absence of an electrostatic repulsion. The $5 R$ mutant samples exhibited higher polydispersities than the other mutants ( $\sim 20 \%$ compared to $<10 \%$ ). High polydispersities are indicative of small oligomer formation, and therefore make interpretation of $k_{\mathrm{D}}$ values in terms of simplified potential models more difficult.

On the other hand, the $5 \mathrm{E}$ mutant exhibited the strongest protein-protein attraction of all the variants in solution without sodium chloride ( $k_{\mathrm{D}}$ equal to $-9.4 \mathrm{~mL} / \mathrm{g}$ ), which is expected due to the low net charge of $5 \mathrm{E}$ at $\mathrm{pH} 5$. For $5 \mathrm{E}$, the salt-induced increase in $k_{\mathrm{D}}$ reflects the presence of an electrostatic attraction between proteins $[48,55,71]$. This behaviour occurs when proteins have near net neutral charge and large anisotropic charge distributions, which likely arises in $5 \mathrm{E}$, from engineering the negative charge patch on a positively charged scaffold.

The $k_{\mathrm{D}}$ value for $5 \mathrm{~K}$ in solutions with added sodium chloride equal to $-13.0 \mathrm{~mL} / \mathrm{g}$ is much lower than the corresponding value for the wild type equal to $-2.6 \mathrm{~mL} / \mathrm{g}$ indicating the presence of a strong short-ranged attractive interaction. Similarly, the other overcharged mutant $5 \mathrm{R}$ also exhibited enhanced protein-protein attractions relative to the wild type.

\subsection{Thermal ramp dynamic light scattering studies}

Dynamic light scattering (DLS) experiments were recorded as a function of temperature for each of the mutants in solutions at $\mathrm{pH}$ 5 without added salt and with $125 \mathrm{mM}$ sodium chloride. The reported values of $R_{\mathrm{H}}$ are a weighted-average, which biases the measurement towards the aggregate population. Nevertheless, the temperature at which aggregates are initially detected provides a relative indicator for the monomer loss kinetics as the initial formation of aggregates will deplete the monomer population. As such, for each mutant, we define an aggregation onset temperature $\left(T_{\mathrm{DLS}}\right)$ as the temperature when the hydrodynamic size increases by more than $0.1 \mathrm{~nm}$ relative to the previous temperature. At $T_{\mathrm{DLS}}$, we found a large increase in polydispersity above $20 \%$ from cumulant fitting and a transition from a monomodal to a multimodal population (a decrease in monomer peak intensity below 95\%) for all mutants except $5 \mathrm{~K}$ and $5 \mathrm{R}$. The values of $T_{\mathrm{DLS}}$ for samples 
at a concentration of $1 \mathrm{~g} / \mathrm{L}$ are reported in Table 2. For the solution conditions without any added sodium chloride, there is good agreement between the ranking of the mutants according to their $T_{\mathrm{DLS}}$ values and the $T_{\mathrm{NMR}}$ values, where the latter provides a direct measure of the monomer loss as a function of temperature. The overcharged mutants are the least stable mutants according to both measurements, while the 4RK mutant is the most stable. The only discrepancy is the wild type, which exhibits a $T_{\mathrm{DLS}}$ value similar to the salt bridge mutants, but the $T_{\mathrm{NMR}}$ value is more similar to the 4 RK mutant.

In Fig. 5 the measured hydrodynamic sizes are reported as a function of temperature for the wild type, the salt bridge mutants, $4 \mathrm{RK}$, each at different protein concentrations in solutions at $\mathrm{pH} 5$ without added salt. At every protein concentration, the initial onset of aggregation occurs consistently at $1-2{ }^{\circ} \mathrm{C}$ higher for the $1 \mathrm{SB}$ and wild-type when compared against the $2 \mathrm{SB}$ and $3 \mathrm{SB}$ mutants. However, a cross-over temperature is observed where the $R_{\mathrm{H}}$ values for $1 \mathrm{SB}$ and for the wild type become larger than for $2 \mathrm{SB}$ or $3 \mathrm{SB}$. Above this temperature, the main contribution to the average $R_{\mathrm{H}}$ value is from growing aggregates, rather than from any new aggregates formed by nucleation. As such, the smaller $\mathrm{d} R_{\mathrm{h}} / \mathrm{d} T$ values indicate slower aggregate growth rates for 2SB and 3SB when compared against $1 \mathrm{SB}$ or the wild type. Conversely, the lower values of $T_{\mathrm{DLS}}$ for 2SB and 3SB give insight into the relative rates of nucleation. The aggregates detected initially by dynamic light scattering at $T_{\text {DLS }}$ have undergone aggregate growth and nucleation as they are much larger than typically sized nuclei observed in aggregation pathways. However, because 2SB and 3SB exhibit slower aggregate growth, the earlier detection of their aggregates might be indicative of a faster nucleation step compared to 1SB and wild type.

The 4RK mutant exhibits a much slower increase in size than any of the other mutants as the aggregation onset temperature is more than $5{ }^{\circ} \mathrm{C}$ greater than the wild type at all protein concentrations. There is insufficient data to determine whether or not the decreased aggregate formation is due to slower nucleation or slower aggregate growth.

A comparison of the temperature profiles of $R_{\mathrm{H}}$ for $5 \mathrm{E}, 5 \mathrm{~K}$, and $5 \mathrm{R}$ at $\mathrm{pH} 5$ are shown in Fig. 6. The initial increase in $R_{\mathrm{H}}$ was observed at significantly lower temperatures than for the other mutants. The aggregation behaviour exhibited by $5 \mathrm{E}$ follows a similar pattern to the wild type. At $T_{\mathrm{DLS}}$, bimodal distribution of protein sizes was observed indicating the immediate formation of larger aggregates on the timescale of the experiment. This con-

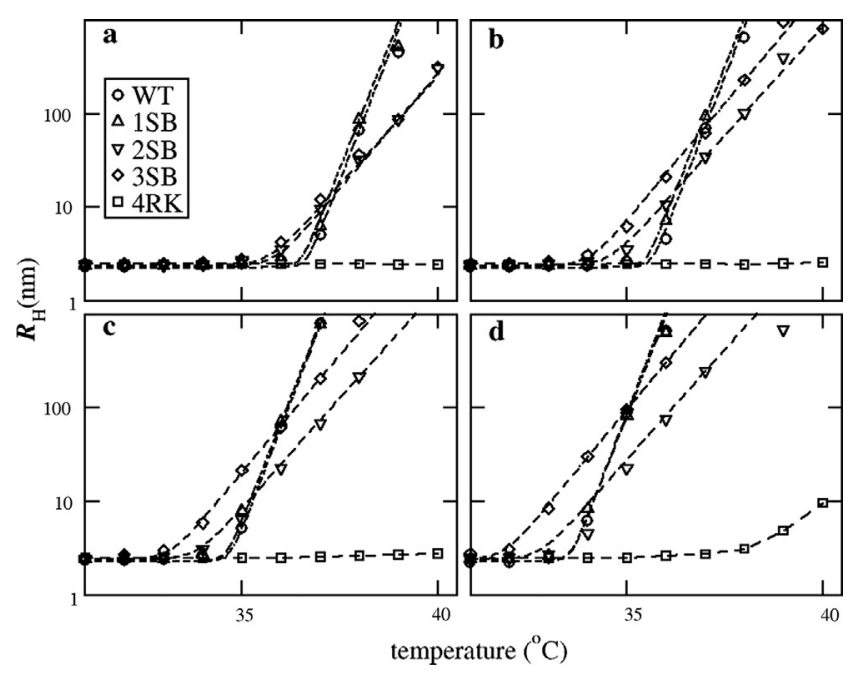

Fig. 5. Hydrodynamic size $R_{\mathrm{H}}$ plotted versus temperature for $\mathrm{WT}, 1 \mathrm{SB}, 2 \mathrm{SB}, 3 \mathrm{SB}, 4 \mathrm{RK}$ in solutions at $\mathrm{pH} 5$ without sodium chloride at different protein concentrations (a) $1 \mathrm{~g} / \mathrm{L}$, (b) $2 \mathrm{~g} / \mathrm{L}$, (c) $4 \mathrm{~g} / \mathrm{L}$, (d) $9 \mathrm{~g} / \mathrm{L}$. Lines are drawn as a guide to the eye.

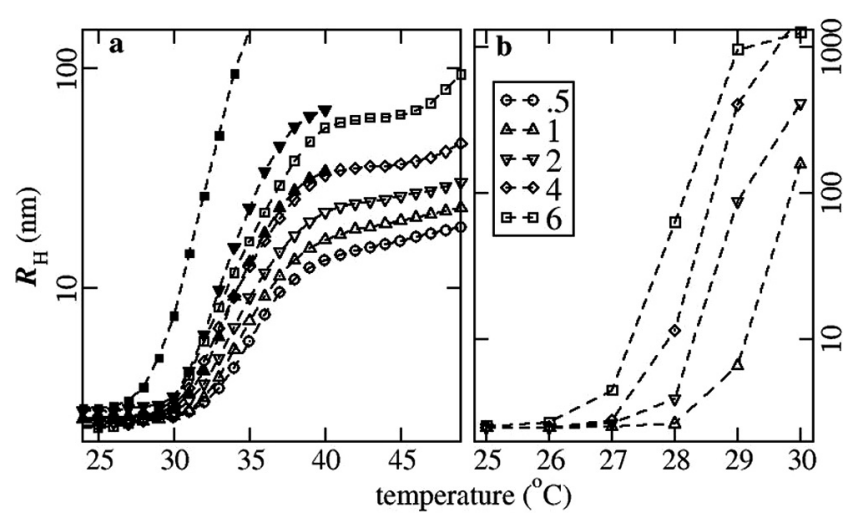

Fig. 6. Hydrodynamic size $R_{\mathrm{H}}$ plotted versus temperature for solutions at $\mathrm{pH} 5$ without sodium chloride at varying protein concentration for (a) $5 \mathrm{~K}$ (open symbols) and 5R (closed symbols), and (b) 5E. Protein concentrations shown in legend have units of $\mathrm{g} / \mathrm{L}$. Lines are drawn as a guide to the eye.

trasts with the behaviour exhibited by the $5 \mathrm{~K}$ and $5 \mathrm{R}$ mutants. For the $5 \mathrm{~K}$ and $5 \mathrm{R}$ mutants, the measured correlation function can be fitted to a monomodal population at temperatures up to 5 degrees greater than the aggregation onset temperature. Decreased aggregate growth rates of $5 \mathrm{R}$ or $5 \mathrm{~K}$ are immediately apparent from comparing the $R_{\mathrm{H}}$ values shown in Fig. 5a for the wild type and Fig. 6 a for either $5 \mathrm{R}$ or $5 \mathrm{~K}$. At a protein concentration of $1 \mathrm{~g} / \mathrm{L}$, wild type aggregates are not detected until $37^{\circ} \mathrm{C}$, while aggregates of $5 \mathrm{R}$ or $5 \mathrm{~K}$ are formed at $32{ }^{\circ} \mathrm{C}$. However, at $38^{\circ} \mathrm{C}$, the $R_{\mathrm{H}}$ values are already greater for the wild type than for $5 \mathrm{R}$ or $5 \mathrm{~K}$.

The lower values of $T_{\mathrm{DLS}}$ for the overcharged mutants indicate faster rates of nucleation and monomer loss kinetics relative to the wild type. As mentioned previously, we do not know a priori if aggregates detected initially by dynamic light scattering reflect only the nucleation step or nucleation and aggregate growth. However, as $5 \mathrm{~K}$ and $5 \mathrm{R}$ exhibit slower aggregate growth, the earlier onset of aggregation can only be rationalized in terms of a faster nucleation step.

A similar set of dynamic light scattering experiments was carried out for each of the mutants at $\mathrm{pH} 5$ with a sodium chloride concentration of $125 \mathrm{mM}$. For all mutants, when adding $125 \mathrm{mM}$ sodium chloride, there is on average a $10{ }^{\circ} \mathrm{C}$ drop in $T_{\text {DLS }}$ as tabulated in Table 2. Qualitatively different behaviour was observed in solutions with sodium chloride than without. There was a much larger increase in $R_{\mathrm{H}}$ immediately after the initial onset of aggregation. The aggregation behaviour of all mutants appeared to be more stochastic, where $T_{\text {DLS }}$ varied by up to 3 or $4{ }^{\circ} \mathrm{C}$ for samples at the same solution condition and protein concentration. The mutants can be broken up into three groups based on their onsets of aggregation $T_{\mathrm{DLS}}$. Mutants $5 \mathrm{E}, 5 \mathrm{~K}$, and $3 \mathrm{SB}$ aggregated at the lowest temperature, whereas $4 \mathrm{RK}$ aggregated at the highest temperature and the other mutants aggregated at intermediate temperatures.

\subsection{Temperature-ramped static light scattering experiments}

Static light scattering profiles have been measured as a function of temperature for each mutant in solutions at four different sodium chloride concentrations at either $\mathrm{pH} 5$ or at $\mathrm{pH} 7$. By systematically varying the $\mathrm{pH}$ and increasing salt concentration provides insight into the role of electrostatic interactions. Representing data in terms of fitting parameters provides a manageable way for comparing behaviour across the large factorial of experimental conditions (mutants and solution conditions) studied here. Initially each of the light scattering profiles was fit to Eq. (3) to give the values of $E_{\mathrm{a}}$ and $T_{\mathrm{SLS}}$ shown in Table $3 \mathrm{a}$ and $\mathrm{b}$. The light scattering profiles can only be compared with each other in terms 


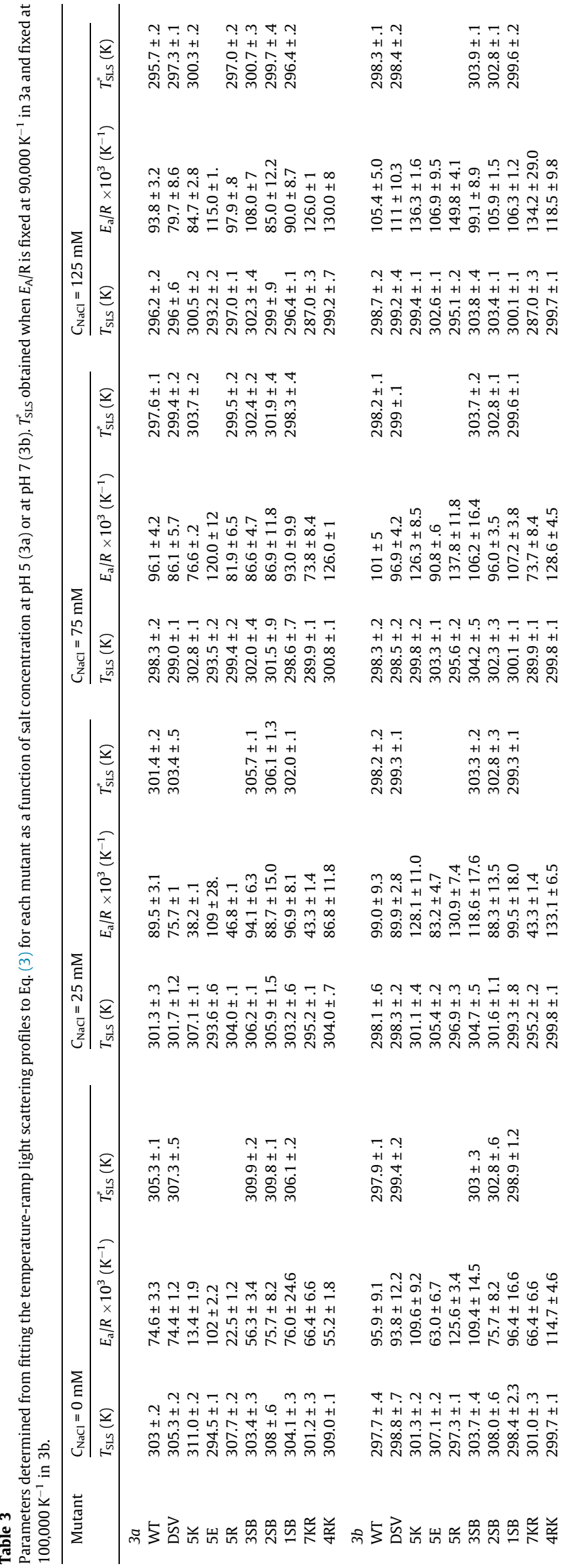

of $T_{\mathrm{SLS}}$ values obtained for the same $E_{\mathrm{a}}$ value due to the strong correlations between these parameters. As such, the data were also fitted while holding $E_{\mathrm{a}}$ fixed. For the wild-type, DSV, and salt bridge mutants, when fitting both parameters, $E_{\mathrm{a}}$ slightly increases when increasing sodium chloride concentration from 0 to $25 \mathrm{mM}$, after which it remains relatively constant at $90,000 \mathrm{~K}^{-1}$ for the solutions at $\mathrm{pH} 5$ and at $100,000 \mathrm{~K}^{-1}$ for $\mathrm{pH}$ 7. These values were constrained in the fitting to determine the $T_{\mathrm{SLS}}^{*}$ values shown in Table 3 , where we use the * to denote the fit value corresponds to constraining $E_{\mathrm{a}}$. In all cases, a goodness of fit $r^{2}$ value greater than 0.99 was obtained with the exception of the 3SB $\left(r^{2}=0.95\right)$ mutant at $25 \mathrm{mM}$ ionic strength at $\mathrm{pH}$. The experimental and fit temperature profiles for the wild type and the salt bridge mutants 1SB, $2 \mathrm{SB}$, and 3SB at pH 5 without added salt and with $125 \mathrm{mM}$ sodium chloride are compared in Fig. 7a through d. For the mutants 5R, 5K, $5 \mathrm{E}, 4 \mathrm{RK}$, and $7 \mathrm{KR}$, reasonable fits to the data are only obtained when varying $E_{\mathrm{a}}$ and $T_{\mathrm{SLS}}$, except for $5 \mathrm{~K}$ or $5 \mathrm{R}$ at higher salt concentrations with pH equal to 5 , when reasonable fits are obtained with $E_{\mathrm{a}}$ equal to $90,000 \mathrm{~K}^{-1}$.

The fitted values of $T_{S L S}^{*}$ for the wild-type, salt bridge mutants, and DSV are shown graphically in Fig. $8 \mathrm{a}$ and b. The meaning of $T_{\mathrm{SLS}}^{*}$ is clear from comparing the values to the light scattering profiles shown in Fig. 7. For the wild type and each of the salt bridge mutants, the approximate $10^{\circ} \mathrm{C}$ decrease in $T_{\mathrm{SLS}}^{*}$ when increasing sodium chloride concentration from 0 to $125 \mathrm{mM}$ corresponds to

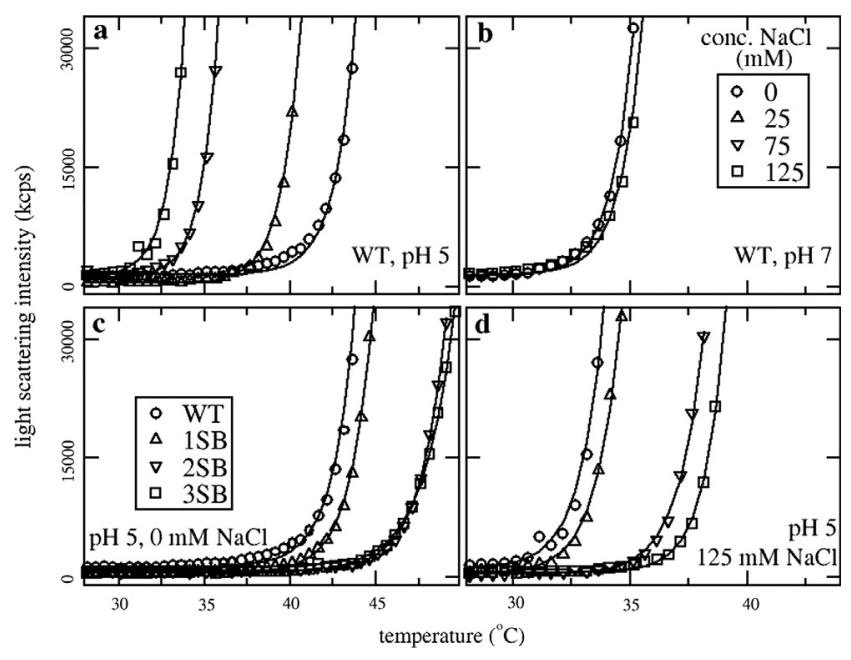

Fig. 7. Static light scattering profiles shown as a function of temperature for wild type (WT) in solutions with varying sodium chloride concentration at (a) $\mathrm{pH} 5$ and at (b) pH 7, and for WT, $1 \mathrm{SB}, 2 \mathrm{SB}$, and 3SB in solutions at $\mathrm{pH} 5$ (c) without sodium chloride and (d) with $125 \mathrm{mM}$ sodium chloride. Solid lines are fits to Eq. (3), where fit parameters are given in Table 3a. All samples are at a protein concentration of $1 \mathrm{~g} / \mathrm{L}$.

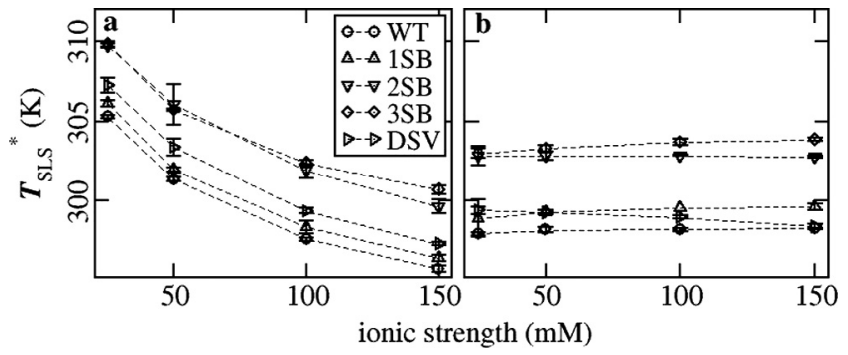

Fig. 8. Fit values of $T_{\mathrm{SLS}}^{*}$ plotted versus ionic strength for WT, $1 \mathrm{SB}, 2 \mathrm{SB}, 3 \mathrm{SB}$, DSV in solutions (a) at $\mathrm{pH} 5$ and (b) at $\mathrm{pH} 7$. 
the shift along the temperature axis in the corresponding experimental light scattering curve.

\section{Discussion}

\subsection{Changes in $T_{S L S}^{*}$ reflect relative aggregate growth rates}

The time evolution of aggregate population is expected to reflect both the rate of aggregate growth and the rate of nucleation, as nucleation determines the initial concentration of seeds or nuclei. However, because changes to only one parameter $T_{\mathrm{SLS}}^{*}$ are required to capture differences in the light scattering profiles, the data can be differentiated from each other based on only one characteristic rate constant. The characteristic timescale is most likely related to an aggregate growth rate as the fitting is sensitive to the part of the profile where the light scattering reading is biased towards the aggregate population. A similar observation has been made from isothermal measurements of light scattering profiles for a range of antibody molecules under different solution conditions (e.g. temperature, $\mathrm{pH}$, and for various salt types). The profiles collapse on a master curve when rescaled by a characteristic aggregate growth rate constant $[5,73]$. This universal behaviour is predicted using population balance modelling only when the nucleation step can be neglected and when aggregate growth occurs through the same pathway dominated by aggregateaggregate coalescence rather than by chain polymerization [5].

As such, we expect $T_{\mathrm{SLS}}^{*}$ values to reflect relative growth rates; a decrease in $T_{\mathrm{SLS}}^{*}$ will correlate with an increase in aggregate growth rate. The corresponding ranking of the mutants at $\mathrm{pH} 5$ follows the order $1 \mathrm{SB} \sim$ wild type $>2 \mathrm{SB} \sim 3 \mathrm{SB}$, which is remarkably similar to that observed in the dynamic light scattering experiment. Indeed, similar $R_{\mathrm{H}}$ profiles (shown in Fig. 5a) are observed for wild type and $1 \mathrm{SB}$ and for 2SB and 3SB, where the latter grouping exhibits the slower aggregate growth (as reflected by the lower $\mathrm{d} R_{\mathrm{H}} / \mathrm{dT}$ values).

The ionic strength and $\mathrm{pH}$ trends of $T_{\mathrm{SLS}}^{*}$ reflect the expected changes in aggregate growth rates due to the impact of electrostatic interactions, which has been rationalized using DLVO theory $[5,19,63]$. A non-specific increase in aggregate growth rates occurs when the repulsive double-layer forces are reduced either by changing $\mathrm{pH}$ to reduce protein net charge or by electrostatic screening through increasing in the ionic strength $[5,43,47,60,61,63,66]$. The electrostatic interactions are greater for the scFv at $\mathrm{pH} 5$ versus pH 7 due the larger net charge (see Table 1 for theoretical estimation of net charge). As such, the decrease in $T_{\mathrm{SLS}}^{*}$ for each mutant at $\mathrm{pH} 5$ with increasing sodium chloride concentration is due to screening electrostatic repulsion between growth units. At pH 7 , the values of $T_{\mathrm{SLS}}^{*}$ remain invariant with ionic strength indicating no electrostatic repulsion as expected since the proteins have a net charge close to $0 e$.

A key question is why the static light scattering profiles are insensitive to changes in nucleation rates for the systems described by the same activation energy. One possibility is that nucleation rates are similar across the corresponding set of mutants and ionic strength conditions. This seems plausible when comparing the behaviour of the mutants in solutions at $\mathrm{pH} 5$ without added salt as the initial onset of aggregation (as reflected by the $T_{\mathrm{DLS}}$ values shown in Table 2) across the wild type and salt bridge mutants varies only by $1{ }^{\circ} \mathrm{C}$. However, for each mutant, when increasing sodium chloride concentration to $125 \mathrm{mM}$, there is a substantial decrease in the $T_{\mathrm{DLS}}$ values. Possibly, the earlier onset of aggregate detection at high salt is due to an increase in aggregate growth rate, rather than increased nucleation. However, if this was true, the salt-induced changes to the $T_{\mathrm{DLS}}$ values and $T_{\mathrm{SLS}}^{*}$ values should follow similar trends. This observation holds true for all mutants except 3SB, which has an earlier onset of aggregation, even though the aggregate growth rate appears to be slower compared to the other salt bridge mutants and wild type.

\subsection{The patch-charged mutants}

The dynamic light scattering and NMR studies indicated that introducing either a positive or negative charged patch on the scFv caused significant changes to both the nucleation and aggregate growth rates. The measured static light scattering profiles as a function of $\mathrm{pH}$ and ionic strength for the overcharged mutants $5 \mathrm{~K}$ and 5R shown in Fig. 9 provide additional insights into how electrostatic interactions alter their aggregate growth steps. The behaviour observed for $5 \mathrm{~K}$ and $5 \mathrm{R}$ at low ionic strength is consistent with the dynamic light scattering studies indicating these mutants exhibit much lower aggregate growth rates. Changing ionic strength has a dramatic effect on the light scattering profiles indicating strong repulsive electrostatic interactions between aggregating units at low ionic strength, which is due to increased net charges on $5 \mathrm{~K}$ or $5 \mathrm{R}$ due to mutation.

The dramatic changes in aggregate growth behaviour observed for the $5 \mathrm{R}$ and $5 \mathrm{~K}$ mutants reflect a change in growth pathways with increasing ionic strength, which has been previously observed for proteins such as $\alpha$-chymotrypsinogen [51] and a handful of monoclonal antibodies $[8,9,43,75]$. With decreasing strength of electrostatic interactions, there is a transition from nucleation dominated growth (aggregates form but do not grow) to chain polymerization (aggregates only grow by addition of monomers or small building blocks) to aggregate-aggregate coalescence and finally to aggregate precipitation. At $\mathrm{pH} 5$, for both $5 \mathrm{R}$ and $5 \mathrm{~K}$, dynamic light scattering indicates a monomodal size population with low polydispersity reflecting the presence of small oligomers with size just greater than monomer. With increasing temperature further, a bimodal population distribution develops indicating oligomers grow to form larger aggregates, but the large aggregates do not precipitate even at the highest temperature of $90{ }^{\circ} \mathrm{C}$ measured during the static light scattering experiment. This behaviour reflects conditions with strong electrostatic repulsion, where nucleation dominated growth followed by chain polymerization occur with increasing time or temperature $[10,71,75]$. This pattern should be contrasted with what happens when electrostatic repul-

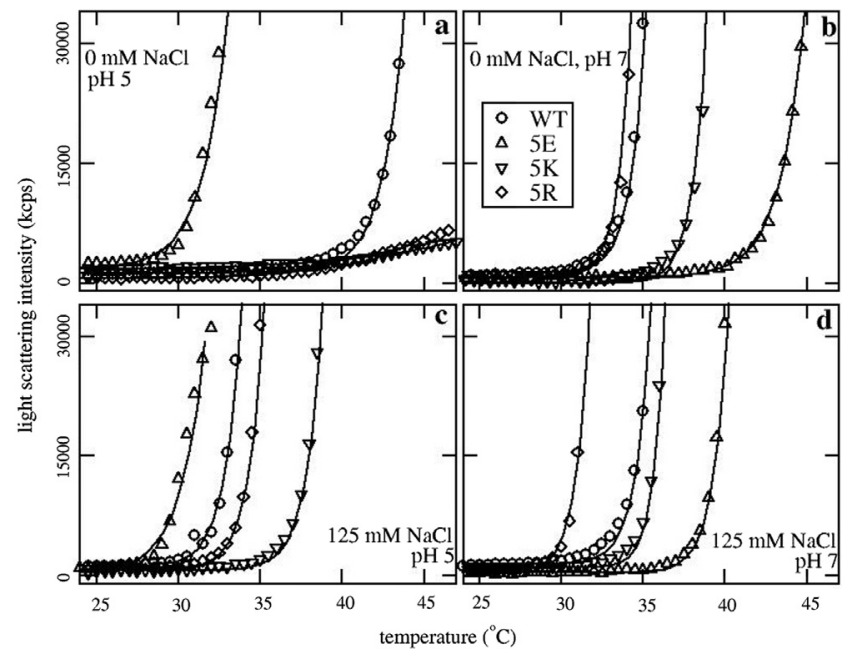

Fig. 9. Static light scattering profiles shown as a function of temperature for WT, $5 E$ $5 \mathrm{~K}$, and $5 \mathrm{R}$ in solutions at (a) $\mathrm{pH} 5$ without sodium chloride, (b) $\mathrm{pH} 7$ without sodium chloride, (c) pH 5 with $125 \mathrm{mM}$ sodium chloride, and (d) pH 7 with $125 \mathrm{mM}$ sodium chloride. Solid lines are fits to Eq. (3), where fit parameters are given in Table $3 \mathrm{a}$ and $\mathrm{b}$. All samples are at a protein concentration of $1 \mathrm{~g} / \mathrm{L}$. 
sion is weakened by increasing ionic strength. For $5 \mathrm{R}$ and $5 \mathrm{~K}$ with $125 \mathrm{mM}$ sodium chloride, at the temperature onset of aggregation, there is a bimodal size population with high polydispersity indicating immediate formation of large aggregates. Further, aggregate precipitation occurs at higher temperatures in the static light scattering experiment. Similar characteristics are observed for the other scFv proteins (WT, 1SB, 2SB, 3SB, and DSV) at all salt concentrations. This behaviour reflect aggregation pathways governed by much weaker electrostatic interactions, where aggregate growth initially occurs through chain polymerization followed by aggregate-aggregate condensation and then precipitation either with increasing time or temperature $[11,75]$.

$5 \mathrm{~K}$ and $5 \mathrm{R}$ exhibit other characteristics observed in the aggregation behaviour of highly charged proteins such as antibodies $[11,43,75]$ and $\boldsymbol{\alpha}$-chymotrypsinogen [51] in acidic conditions. The increase in net positive charge at low $\mathrm{pH}$ causes an increase in intramolecular charge repulsion and a reduced conformational stability. This, in turn, correlates with a faster nucleation step and increased monomer loss kinetics. We also find introducing the charged patch on $5 \mathrm{~K}, 5 \mathrm{R}$, (and $5 \mathrm{E}$ ) leads to a lower conformational stability as is evident from the lower denaturant midpoint concentration relative to the wild type. Conversely, the faster monomer loss kinetics have been inferred from the NMR and dynamic light scattering studies.

The 5E mutant at pH 5 exhibited the fastest aggregate growth rates as reflected by the dynamic light scattering experiment (see Fig. 6b) or according to the static light scattering profile shown in Fig. 9a and c. Part of the reason is likely due to the absence of any electrostatic repulsion as the theoretical net charge of $5 \mathrm{E}$ at pH 5 (equal to 1.6e) is much less than any of the other mutants. Further, introducing a negatively charged patch on a positive scaffold creates a large anisotropic charge distribution, which also causes an electrostatic-driven self association. This behaviour is consistent with the increase in the $k_{\mathrm{D}}$ value for $5 \mathrm{E}$ when adding sodium chloride. Previous studies have found a strong correlation between increased aggregation rates and electrostatic selfassociation $[13,55,80,99]$, which might also explain the increased aggregation of $5 \mathrm{E}$.

In contrast, at $\mathrm{pH} 7$, the aggregate growth rates of the $5 \mathrm{E}$ mutant with and without added sodium chloride are reduced relative to the $5 \mathrm{R}$ or $5 \mathrm{~K}$ mutants as indicated by the reduced light scattering profiles shown by Fig. $7 \mathrm{~b}$ and $\mathrm{d}$, even though the absolute net charge calculated for $5 \mathrm{E}$ is less than that for either $5 \mathrm{R}$ or $5 \mathrm{~K}$ (see Table 1 ). The results suggest that patch-charging with acidic versus basic groups is more effective when introducing charge on a near net neutral template. Negatively charged groups also appear to be more effective at preventing self-association of the native protein at moderate salt concentrations when electrostatic interactions are sufficiently screened. In solutions at pH 5 with $125 \mathrm{mM}$ sodium chloride, the $k_{\mathrm{D}}$ value for $5 \mathrm{E}$ is much greater than either the $5 \mathrm{~K}$ or $5 \mathrm{R}$ mutant (see Table 2). The increased solubility observed here of negative versus positive charged groups has also been deduced from mutation studies of Ribonuclease SA [89] and from the salting-out behaviour for a series of seven proteins [44].

\subsection{Correlations between $k_{D}$ and aggregation propensity}

Much recent research has explored the link between proteinprotein interactions, recorded through $B_{22}$ or $k_{\mathrm{D}}$ measurements, and aggregation behaviour, usually probed under non-native or accelerated conditions. A decreasing $k_{\mathrm{D}}$ value is often correlated with increased aggregation propensity when reducing electrostatic repulsion by increasing ionic strength or using a salt or buffer ion that neutralizes protein charge $[35,46,57,74,78,82,19,46,63,77,81]$. Consistent with these studies, for the wild-type, SB and DSV mutants, the relative rates of aggregate growth (as reflected by the corresponding $T_{S L S}^{*}$ values) and protein-protein interactions (as reflected by the $k_{\mathrm{D}}$ values) decrease non-specifically upon addition of $\mathrm{NaCl}$ due to screening of electrostatic interactions. Mechanistically, a reduction in growth rates occurs due to a cross-over in aggregation pathways from aggregate-aggregate coalescence to chain polymerization to nucleation dominated growth, which has also been correlated with native-state protein-protein interactions in terms of $B_{22}$ values $[9,43,75]$. The overcharged mutants, $5 \mathrm{R}$ and $5 \mathrm{~K}$, both exhibit a similar ordering of aggregate growth mechanisms with reducing sodium chloride concentration at $\mathrm{pH} 5$ reflecting a strong electrostatic repulsion arising from the increased protein net charge. The electrostatic repulsion should also be reflected by the native-state protein-protein interactions. Indeed the $k_{\mathrm{D}}$ value for $5 \mathrm{~K}$ is much larger than for the wild type as expected, but the corresponding $k_{\mathrm{D}}$ value for $5 \mathrm{R}$ is surprisingly lower. As such, for the $5 R$ mutant, the charged properties of the protein, rather than the value for $k_{\mathrm{D}}$, provide a better predictor for the aggregate growth behaviour. We expect the electrostatic repulsion exists when in the native state, but is hidden by the presence of strong self-association as $k_{\mathrm{D}}$ values reflect an averaged protein-protein interaction.

It is also of interest to examine other correlations of the native state protein-protein interactions with aggregate growth rates. There is no clear relationship when correlating $k_{\mathrm{D}}$ values for the wild type and the set of mutants $1 \mathrm{SB}, 2 \mathrm{SB}, 3 \mathrm{SB}$, and DSV and their corresponding $T_{\mathrm{SLS}}^{*}$ values obtained at $125 \mathrm{mM}$ sodium chloride. As a good example, out of this group, the slowest aggregate growth rates are observed for 3SB, but 3SB exhibits the strongest selfassociation (or lowest $k_{\mathrm{D}}$ value). Another example is given by comparing the $5 \mathrm{~K}$ mutant to the wild type in solutions at $\mathrm{pH} 5$ with $125 \mathrm{mM}$ sodium chloride. The static light scattering profile shown in Fig. $9 \mathrm{c}$ for $5 \mathrm{~K}$ is accurately fit to determine a $T_{\mathrm{SLS}}^{*}$ value equal to $303.2 \mathrm{~K}$ (see Table $3 \mathrm{a}$ ). This value is much greater than that for the wild type indicating a slower aggregate growth rate, even though $5 \mathrm{~K}$ exhibits the strongest native-state association out of any mutant $\left(k_{\mathrm{D}}=-13.0 \mathrm{~mL} / \mathrm{g}\right)$. These examples indicate the association steps involved in aggregate growth are determined by partially unfolded regions of the protein that do not contribute to native state protein-protein interactions [4].

\subsection{Lysine protects partially unfolded regions from associating}

The $5 \mathrm{~K}$ mutant is more resistant to aggregation than the $5 \mathrm{R}$ mutant under all solution conditions. In solutions without added salt at $\mathrm{pH} \mathrm{5}$, both mutants appear to exhibit nucleationdominated growth with similar onset temperatures of aggregation. However, when comparing $5 \mathrm{R}$ to $5 \mathrm{~K}$, the sizes of soluble oligomers are larger and a population of large aggregates is detected at a much lower temperature. At moderate ionic strength, 5R forms larger aggregates than $5 \mathrm{~K}$ over all temperatures investigated. In Fig. 10, the static light scattering profiles are shown for the argininelysine swap mutants and the wild type in solutions at $\mathrm{pH} 5$. The increased aggregation resistance of $4 \mathrm{RK}$ and, conversely, the decreased resistance of 7KR provides additional support that arginine to lysine mutations can stabilize proteins against aggregation.

In all cases, swapping arginine for lysine leads to reduced aggregate formation and growth. For $7 \mathrm{KR}$, the increased aggregation propensity is correlated with a slightly lower $k_{\mathrm{D}}$ value reflecting more attractive interactions between the native-state proteins. However, the increased aggregation resistance of 4RK over the wild type does not correlate with increased conformational stability or reduced native-state protein-protein attraction; the $k_{\mathrm{D}}$ values for 4RK are similar to wild type at low and high sodium chloride concentration. At high salt concentration, 5K exhibits the greatest native-state self association, but $5 R$ exhibits faster aggregation kinetics. As such, the stabilizing effectiveness must be related to 


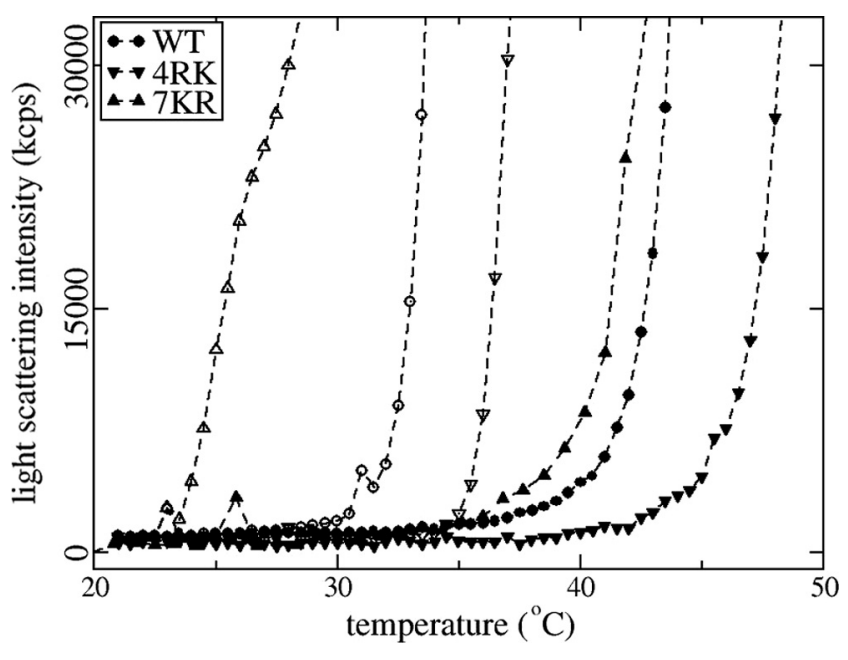

Fig. 10. Static light scattering profile as a function of temperature for WT, $4 R K$ and $7 \mathrm{KR}$ in solutions at $\mathrm{pH} 5$ without sodium chloride (closed symbols) and with $125 \mathrm{mM}$ sodium chloride (open symbols).

the ability of lysine groups to reduce interactions between partially folded states. We stress that the location of the mutations are especially important. Swapping arginine for lysine on the natively folded protein does not lead to any measurable differences in interactions. As such, we postulate aggregation can only be suppressed by introducing extra 'lysines' on protein surfaces when they occur next to partially unfolded regions that expose hot spots buried during nucleation or aggregate growth. The molecular basis for the increased protective ability of lysine over arginine is determined by a couple of factors. Surveys of crystal databases indicate an increased propensity for arginine to be buried in crystal contacts and functional interfaces while lysine groups occur on the rims of crystal contact interfaces $[23,24,38,64]$. These increased solubilizing effects of lysine have been attributed to the high conformational entropy of lysine and the preference of arginine to form cation-pi interactions with aromatic groups [22,30,56].

\section{Conclusions}

The main aims of this study were two-fold, the first was to provide a more in-depth study of how native-state proteinprotein interactions relate to aggregation rates, while the second was to understand better the structural determinants of aggregation propensity. We have largely succeeded in the first task. We have confirmed previous studies indicating that native-state electrostatic interactions correlate with aggregate growth pathways $[9,43,71,75]$ and growth rates $[5,19,63]$, although, we have highlighted a protein, the $5 \mathrm{R}$ mutant, where the native-state electrostatic interactions are not apparent from the value of $k_{\mathrm{D}}$. As such a better indicator of electrostatic interactions might be a direct quantification of the protein electrostatic properties either by theoretical calculations or by experimental verification using electrophoretic measurements. The latter would be more preferred as some commonly-used buffers or salts neutralize protein electrostatic properties $[40,41,46,72]$, which would not be reflected by a theoretical calculation. More importantly, we have provided examples where aggregation does not correlate with conformational stability and native-state protein-protein interactions. As such, there will be limited utility of using $k_{\mathrm{D}}$ values as a predictor for aggregate growth rates in the absence of strong electrostatic interactions $[7,78]$.

The more demanding task is to identify structural mutations that reduce aggregation propensity and then to rationalize the mechanism as to make the mutational strategy more broadly applicable to other systems. Comparing the behaviour of salt bridge mutants to the wild type indicates the location of the second engineered salt bridge is involved in aggregate growth. The aggregate growth rates for 1SB and wild type and for 2SB and 3SB are similar; only changing the second salt bridge has a significant impact on aggregate growth. As such, this region of the scFv provides an ideal location for studying the impact of other mutations on aggregate growth rates. For the arginine-lysine swap mutants, we have not attempted to identify what regions of the protein surface are involved in aggregation. Nevertheless, we have still gained some important insights. A key problem is to determine the structural requisites that determine the stickiness of partially unfolded regions. One approach for biopharmaceutical aggregation $[93,76]$ is to use primary-sequenced base aggregation predictors that have been primarily developed for amyloid formation by natively unfolded proteins $[21,90,29]$. We note these predictors do not distinguish between the aggregation suppression effects of lysine over arginine indicating that there are additional factors that control association rates or energetics between partially folded states involved in nucleation or aggregate growth. While these findings are only preliminary, they offer a good starting point for future studies.

\section{Conflict of interest}

The authors declare no conflict of interest that would influence the submitted work.

\section{Acknowledgements}

The authors would like to acknowledge BBSRC grants BB/ M006913/1 and BB/I017194/1, Wyatt Technologies for use of the DynaPro Plate Reader and Unchained Labs for use of the Optim 1000. We would also like to acknowledge Christopher Roberts for helpful discussions.

\section{Appendix A. Supplementary material}

Supplementary data associated with this article can be found, in the online version, at http://dx.doi.org/10.1016/j.ejpb.2017.01.019.

\section{References}

[1] J.M. Andrews, C.J. Roberts, Non-native aggregation of alphachymotrypsinogen occurs through nucleation and growth with competing nucleus sizes and negative activation energies, Biochemistry 46 (2007) 75587571.

[2] J.M. Andrews, C.J. Roberts, A Lumry-Eyring nucleated polymerization mode of protein aggregation kinetics: 1. Aggregation with pre-equilibrated unfolding. J. Phys. Chem. B 111 (2007) 7897-7913.

[3] M. Arbabi-Ghahroudi, R. To, N. Gaudette, T. Hirama, W. Ding, R. MacKenzie, J. Tanha, Aggregation-resistant VHs selected by in vitro evolution tend to have disulfide-bonded loops and acidic isoelectric points, Protein Eng. Des. Sel. 22 (2009) 59-66.

[4] P. Arosio, S. Rima, M. Morbidelli, Aggregation mechanism of an IgG2 and two IgG1 monoclonal antibodies at low $\mathrm{pH}$ : from oligomers to larger aggregates Pharm. Res. 30 (2013) 641-654.

[5] P. Arosio, S. Rima, M. Lattuada, M. Morbidelli, Population balance modeling of antibodies aggregation kinetics, J. Phys. Chem. B 116 (2012) 7066-7075.

[6] D. Arzensek, D. Kuzman, R. Podgornik, Colloidal interactions between monoclonal antibodies in aqueous solutions, J. Colloid Interf. Sci. 384 (2012) 207-216.

[7] H. Bajaj, V.K. Sharma, A. Badkar, D. Zeng, S. Nema, D.S. Kalonia, Protein structural conformation and not second virial coefficient relates to long-term irreversible aggregation of a monoclonal antibody and ovalbumin in solution, Pharm. Res. 23 (2006) 1382-1394.

[8] G.V. Barnett, V.I. Razinkov, B.A. Kerwin, T.M. Laue, A.H. Woodka, P.D. Butler, T Perevozchikova, C.J. Roberts, Specific-ion effects on the aggregation mechanisms and protein-protein interactions for anti-streptavidin immunoglobulin gamma-1, J. Phys. Chem. B 119 (2015) 5793-5804. 
[9] R.K. Brummitt, D.P. Nesta, L. Chang, A.M. Kroetsch, C.J. Roberts, Nonnative aggregation of an IgG1 antibody in acidic conditions, Part 2: nucleation and growth kinetics with competing growth mechanisms, J. Pharm. Sci. 100 (2011) 2104-2119.

[10] R.K. Brummitt, D.P. Nesta, L.Q. Chang, S.F. Chase, T.M. Laue, C.J. Roberts, Nonnative aggregation of an IgG1 antibody in acidic conditions: Part 1. Unfolding, colloidal interactions, and formation of high-molecular-weight aggregates, J. Pharm. Sci. 100 (2011) 2087-2103.

[11] R.K. Brummitt, D.P. Nesta, L. Chang, S.F. Chase, T.M. Laue, C.J. Roberts, Nonnative aggregation of an IgG1 antibody in acidic conditions: Part 1. Unfolding, colloidal interactions, and formation of high-molecular-weight aggregates, J. Pharm. Sci. 100 (2011) 2087-2103.

[12] I.D. Campbell, The evolution of protein NMR, Biomed. Spectrosc. Imaging 2 (2013) 245-264.

[13] R. Chari, K. Jerath, A.V. Badkar, D.S. Kalonia, Long-and short-range electrostatic interactions affect the rheology of highly concentrated antibody solutions, Pharm. Res. 26 (2009) 2607-2618.

[14] R. Chari, S.N. Singh, S. Yadav, D.N. Brems, D.S. Kalonia, Determination of the dipole moments of RNAse SA wild type and a basic mutant, Proteins: Struct. Funct. Bioinf. 80 (2012) 1041-1052.

[15] R. Chaudhuri, Y. Cheng, C.R. Middaugh, D.B. Volkin, High-throughput biophysical analysis of protein therapeutics to examine interrelationships between aggregate formation and conformational stability, AAPS J. 16 (2014) 48-64.

[16] W. Cheng, S.B. Joshi, F. He, D.N. Brems, B. He, B.A. Kerwin, D.B. Volkin, C.R. Middaugh, Comparison of high-throughput biophysical methods to identify stabilizing excipients for a model IgG2 monoclonal antibody: conformational stability and kinetic aggregation measurements, J. Pharm. Sci. 101 (2012) $1701-1720$.

[17] N. Chennamsetty, V. Voynov, V. Kayser, B. Helk, B.L. Trout, Design of therapeutic proteins with enhanced stability, Proc. Natl. Acad. Sci. USA 106 (2009) 11937-11942.

[18] N. Chennamsetty, V. Voynov, V. Kayser, B. Helk, B.L. Trout, Prediction of aggregation prone regions of therapeutic proteins, J. Phys. Chem. B 114 (2010) 6614-6624.

[19] E.Y. Chi, S. Krishnan, T.W. Randolph, J.F. Carpenter, Physical stability of proteins in aqueous solution: mechanism and driving forces in nonnative protein aggregation, Pharm. Res. 20 (2003) 1325-1336.

[20] C. Cole, J. Warwicker, Side-chain conformational entropy at protein-protein interfaces, Protein Sci. 11 (2002) 2860-2870.

[21] O. Conchillo-Sole, N.S. de Groot, F.X. Aviles, J. Vendrell, X. Daura, S. Ventura AGGRESCAN: a server for the prediction and evaluation of "hot spots" of aggregation in polypeptides, BMS Bioinf. 298 (2007) 1471-1536.

[22] P.B. Crowley, A. Golovin, Cation-pi interactions in protein-protein interfaces, Proteins: Struct. Funct. Bioinf. 59 (2005) 231-239.

[23] J. Czepas, Y. Devedjiev, D. Krowarsch, U. Derewenda, J. Otlewski, Z.S. Derewenda, The impact of Lys $\rightarrow$ Arg surface mutations on the crystallization of the globular domain of RhoGDI, Acta Crystallogr. D 60 (2004) 275-280.

[24] S. Dasgupta, G.H. Iyer, S.H. Bryant, C.E. Lawrence, J.A. Bell, Extent and nature of contacts between protein molecules in crystal lattices and between subunits of protein oligomers, Proteins: Struct. Funct. Bioinf. 28 (1997) 494514.

[25] B.S. Der, C. Kluwe, A.E. Miklos, R. Jacak, S. Lyskov, J.J. Gray, G. Georgiou, A.D. Ellington, B. Kuhlman, Alternative computational protocols for supercharging protein surfaces for reversible unfolding and retention of stability, PLoS ONE 8 (2013) e64363.

[26] K. Dudgeon, K. Famm, D. Christ, Sequence determinants of protein aggregation in human VH domains, Protein Eng. Des. Sel. 22 (2009) 217-220.

[27] K. Dudgeon, R. Rouet, I. Kokmeijer, P. Schofield, J. Stolp, D. Langley, D. Stock, D. Christ, General strategy for the generation of human antibody variable domains with increased aggregation resistance, Proc. Natl. Acad. Sci. USA 109 (2012) 10879-10884.

[28] S. Edwardraja, R. Neelamegam, V. Ramadoss, S. Venkatesan, S.G. Lee, Redesigning of anti-c-Met single chain Fv antibody for the cytoplasmic folding and its structural analysis, Biotechnol. Bioeng. 106 (2010) 367-375.

[29] A.M. Fernandez-Escamilla, F. Rousseau, J. Schymkowitz, L. Serrano, Prediction of sequence-dependent and mutational effects on the aggregation of peptides and proteins, Nat. Biotechnol. 22 (2004) 1302-1306.

[30] M.M. Flocco, S.L. Mowbray, Planar stacking interactions of arginine and aromatic side-chains in proteins, J. Mol. Biol. 235 (1994) 709-717.

[31] S.B. Geng, J.K. Cheung, C. Narasimhan, M. Shameem, P.M. Tessier, Improving monoclonal antibody selection and engineering using measurements of colloidal protein interactions, J. Pharm. Sci. 103 (2014) 3356-3363.

[32] D.S. Goldberg, S.M. Bishop, A.U. Shah, H.A. Sathish, Formulation development of therapeutic monoclonal antibodies using high-throughput fluorescence and static light scattering techniques: role of conformational and colloidal stability, J. Pharm. Sci. 100 (2011) 1306-1315.

[33] A.A. Goldin, Dynals v1. 0 White Paper, 2002.

[34] P. Grancic, V. Illeova, M. Polakovic, J. Sefcik, Thermally induced inactivation and aggregation of urease: experiments and population balance modelling, Chem. Eng. Sci. 70 (2012) 14-21.

[35] F. He, S. Hogan, R.F. Latypov, L.O. Narhi, V.I. Razinkov, High throughput thermostability screening of monoclonal antibody formulations, J. Pharm. Sci. 99 (2010) 1707-1720.
[36] F. He, C.E. Woods, G.W. Becker, L.O. Narhi, V.I. Razinkov, High-throughput assessment of thermal and colloidal stability parameters for monoclonal antibody formulations, J. Pharm. Sci. 100 (2011) 5126-5141.

[37] W.C. Hwang, Y. Lin, E. Santelli, J. Sui, L. Jaroszewski, B. Stec, M. Farzan, W.A. Marasco, R.C. Liddington, Structural basis of neutralization by a human antisevere acute respiratory syndrome spike protein antibody, 80R, J. Biol. Chem. 281 (2006) 34610-34616.

[38] G.H. Iyer, S. Dasgupta, J.A. Bell, Ionic strength and intermolecular contacts in protein crystals, J. Cryst. Growth 217 (2000) 429-440.

[39] L. Jespers, O. Schon, K. Famm, G. Winter, Aggregation-resistant domain antibodies selected on phage by heat denaturation, Nat. Biotechnol. 22 (2004) 1161-1165.

[40] D. Kameoka, E. Masuzaki, T. Ueda, T. Imoto, Effect of buffer species on the unfolding and the aggregation of humanized IgG, J. Biochem. 142 (2007) 383391.

[41] D.S. Katayama, R. Nayar, D.K. Chou, J.J. Valente, J. Cooper, C.S. Henry, D.G. Vander Velde, L. Villarete, C.P. Liu, M.C. Manning, Effect of buffer species on the thermally induced aggregation of interferon-tau, J. Pharm. Sci. 95 (2006) $1212-1226$.

[42] V. Kayser, N. Chennamsetty, V. Voynov, B. Helk, K. Forrer, B.L. Trout, Evaluation of a non-arrhenius model for therapeutic monoclonal antibody aggregation, J. Pharm. Sci. 100 (2011) 2526-2542.

[43] N. Kim, R.L. Remmele Jr., D. Liu, V.I. Razinkov, E.J. Fernandez, C.J. Roberts, Aggregation of anti-streptavidin immunoglobulin gamma-1 involves Fab unfolding and competing growth pathways mediated by $\mathrm{pH}$ and salt concentration, Biophys. Chem. 172 (2013) 26-36.

[44] R.M. Kramer, V.R. Shende, N. Motl, C.N. Pace, J.M. Scholtz, Toward a molecular understanding of protein solubility: increased negative surface charge correlates with increased solubility, Biophys. J. 102 (2012) 1907-1915.

[45] M.S. Lawrence, K.J. Phillips, D.R. Liu, Supercharging proteins can impart unusual resilience, J. Am. Chem. Soc. 129 (2007), 10110-+.

[46] V. Le Brun, W. Friess, S. Bassarab, S. Muhlau, P. Garidel, A critical evaluation of self-interaction chromatography as a predictive tool for the assessment of protein-protein interactions in protein formulation development: a case study of a therapeutic monoclonal antibody, Eur. J. Pharm. Biopharm. 75 (2010) 16-25

[47] C.C. Lee, M.C. Julian, K.E. Tiller, F. Meng, S.E. DuConge, R. Akter, D.P. Raleigh, P. M. Tessier, Design and optimization of anti-amyloid domain antibodies specific for $\beta$-amyloid and islet amyloid polypeptide, J. Biol. Chem. 291 (2016) 2858-2873.

[48] W. Li, B.A. Persson, M. Morin, M.A. Behrens, M. Lund, M.Z. Oskolkova, Chargeinduced patchy attractions between proteins, J. Phys. Chem. B 119 (2015) 503-508.

[49] Y. Li, C.J. Roberts, Lumry-eyring nucleated-polymerization model of protein aggregation kinetics. 2. Competing growth via condensation and chain polymerization, J. Phys. Chem. B 113 (2009) 7020-7032.

[50] Y. Li, W.F.I.V. Weiss, C.J. Roberts, Characterization of high-molecular-weight nonnative aggregates and aggregation kinetics by size exclusion chromatography with inline multi-angle laser light scattering, J. Pharm. Sci. 98 (2009) 3997-4016.

[51] Y. Li, B.A. Ogunnaike, C.I. Roberts, Multi-variate approach to global protein aggregation behavior and kinetics: effects of $\mathrm{pH}, \mathrm{NaCl}$, and temperature for alpha-chymotrypsinogen A, J. Pharm. Sci. 99 (2010) 645-662.

[52] Y. Li, H. Mach, J.T. Blue, High throughput formulation screening for global aggregation behaviors of three monoclonal antibodies, J. Pharm. Sci. 100 (2011) 2120-2135.

[53] N.R. Maddux, S.B. Joshi, D.B. Volkin, J.P. Ralston, C.R. Middaugh, Multidimensional methods for the formulation of biopharmaceuticals and vaccines, J. Pharm. Sci. 100 (2011) 4171-4197.

[54] N.R. Maddux, V. Iyer, W. Cheng, A.M.K. Youssef, S.B. Joshi, D.B. Volkin, J.P. Ralston, G. Winter, C.R. Middaugh, High throughput prediction of the longterm stability of pharmaceutical macromolecules from short-term multiinstrument spectroscopic data, J. Pharm. Sci. 103 (2014) 828-839.

[55] P.R. Majhi, R.R. Ganta, R.P. Vanam, E. Seyrek, K. Giger, P.L. Dubin, Electrostatically driven protein aggregation: beta-lactoglobulin at low ionic strength, Langmuir 22 (2006) 9150-9159.

[56] R.L. Martis, S.K. Singh, M.M. Gromiha, C. Santhosh, Role of cation-pi interactions in single chain 'all-alpha' proteins, J. Theor. Biol. 250 (2008) 655-662.

[57] T. Menzen, W. Friess, Temperature-ramped studies on the aggregation, unfolding, and interaction of a therapeutic monoclonal antibody, J. Pharm. Sci. 103 (2014) 445-455.

[58] A.E. Miklos, C. Kluwe, B.S. Der, S. Pai, A. Sircar, R.A. Hughes, M. Berrondo, J. Xu, V. Codrea, P.E. Buckley, Structure-based design of supercharged, highly thermoresistant antibodies, Chem. Biol. 19 (2012) 449-455.

[59] M. Muschol, F. Rosenberger, Interactions in undersaturated and supersaturated lysozyme solutions: static and dynamic light scattering results, J. Chem. Phys. 103 (1995) 10424-10432.

[60] L. Nicoud, P. Arosio, M. Sozo, A. Yates, E. Norrant, M. Morbidelli, Kinetic analysis of the multistep aggregation mechanism of monoclonal antibodies, J. Phys. Chem. B 118 (2014) 10595-10606.

[61] L. Nicoud, M. Sozo, P. Arosio, A. Yates, E. Norrant, M. Morbidelli, Role of cosolutes in the aggregation kinetics of monoclonal antibodies, J. Phys. Chem. B 118 (2014) 11921-11930. 
[62] Frank H. Niesen, Helena Berglund, Masoud Vedadi, The use of differential scanning fluorimetry to detect ligand interactions that promote protein stability, Nat. Protoc. 2 (9) (2007) 2212-2221.

[63] S.N. Olsen, K.B. Andersen, T.W. Randolph, J.F. Carpenter, P. Westh, Role of electrostatic repulsion on colloidal stability of Bacillus halmapalus alphaamylase, Biochim. Biophys. Acta Proteins Proteomics 1794 (2009) 10581065.

[64] D. Pednekar, A. Tendulkar, S. Durani, Electrostatics-defying interaction between arginine termini as a thermodynamic driving force in proteinprotein interaction, Proteins: Struct. Funct. Bioinf. 74 (2009) 155-163.

[65] J.M. Perchiacca, M. Bhattacharya, P.M. Tessier, Mutational analysis of domain antibodies reveals aggregation hotspots within and near the complementarity determining regions, Proteins: Struct. Funct. Bioinf. 79 (2011) 2637-2647.

[66] J.M. Perchiacca, C.C. Lee, P.M. Tessier, Optimal charged mutations in the complementarity-determining regions that prevent domain antibody aggregation are dependent on the antibody scaffold, Protein Eng. Des. Sel. 27 (2014) 29-39.

[67] J.D Ramsey, M.L. Gill, T.J. Kamerzell, E.S. Price, S.B. Joshi, S.M. Bishop, C.N. Oliver, C.R. Middaugh, Using empirical phase diagrams to understand the role of intramolecular dynamics in immunoglobulin G stability, J. Pharm. Sci. 98 (2009) 2432-2447.

[68] T.W. Randolph, J.F. Carpenter, Engineering challenges of protein formulations, AIChE J. 53 (2007) 1902-1907.

[69] C.J. Roberts, T.K. Das, E. Sahin, Predicting solution aggregation rates for therapeutic proteins: approaches and challenges, Int. J. Pharm. 418 (2011) $318-333$.

[70] C.J. Roberts, T.K. Das, E. Sahin, Predicting solution aggregation rates for therapeutic proteins: approaches and challenges, Int. J. Pharm. 418 (2011) 318-333.

[71] D. Roberts, R. Keeling, M. Tracka, C.F. van der Walle, S. Uddin, J. Warwicker, R. Curtis, The role of electrostatics in protein-protein interactions of a monoclonal antibody, Mol. Pharm. 11 (2014) 2475-2489.

[72] D. Roberts, R. Keeling, M. Tracka, C.F. van der Walle, S. Uddin, J. Warwicker, R. Curtis, Specific ion and buffer effects on protein-protein interactions of a monoclonal antibody, Mol. Pharm. 12 (2015) 179-193.

[73] J. Rubin, A. San Miguel, A.S. Bommarius, S.H. Behrens, Correlating aggregation kinetics and stationary diffusion in protein-sodium salt systems observed with dynamic light scattering, J. Phys. Chem. B 114 (2010) 43834387.

[74] J. Rubin, L. Linden, W.M. Coco, A.S. Bommarius, S.H. Behrens, Salt-induced aggregation of a monoclonal human immunoglobulin G1, J. Pharm. Sci. 102 (2013) 377-386.

[75] E. Sahin, A.O. Grillo, M.D. Perkins, C.J. Roberts, Comparative effects of pH and ionic strength on protein-protein interactions, unfolding, and aggregation for IgG1 antibodies, J. Pharm. Sci. 99 (2010) 4830-4848.

[76] E. Sahin, J.L. Jordan, M.L. Spatara, A. Naranjo, J.A. Costanzo, W.F. Weiss, A.S Robinson, E.J. Fernandez, C.J. Roberts, Computational design and biophysical characterization of aggregation-resistant point mutations for gamma D crystallin illustrate a balance of conformational stability and intrinsic aggregation propensity, Biochemistry 50 (2011) 628-639.

[77] K. Saito, H. Ishikita, Energetics of short hydrogen bonds in photoactive yellow protein, Proc. Natl. Acad. Sci. USA 109 (2012) 167-172.

[78] S. Saito, J. Hasegawa, N. Kobayashi, N. Kishi, S. Uchiyama, K. Fukui, Behavior of monoclonal antibodies: relation between the second virial coefficient (B-2) at low concentrations and aggregation propensity and viscosity at high concentrations, Pharm. Res. 29 (2012) 397-410.

[79] S. Saito, J. Hasegawa, N. Kobayashi, T. Tomitsuka, S. Uchiyama, K. Fukui, Effects of ionic strength and sugars on the aggregation propensity of monoclonal antibodies: influence of colloidal and conformational stabilities, Pharm. Res. 30 (2013) 1263-1280.

[80] A. Saluja, A.V. Badkar, D.L. Zeng, S. Nema, D.S. Kalonia, Ultrasonic storage modulus as a novel parameter for analyzing protein-protein interactions in high protein concentration solutions: correlation with static and dynamic light scattering measurements, Biophys. J. 92 (2007) 234-244.

[81] A. Saluja, R.M. Fesinmeyer, S. Hogan, D.N. Brems, Y.R. Gokarn, Diffusion and sedimentation interaction parameters for measuring the second virial coefficient and their utility as predictors of protein aggregation, Biophys. J. 99 (2010) 2657-2665.

[82] A. Saluja, R.M. Fesinmeyer, S. Hogan, D.N. Brems, Y.R. Gokarn, Diffusion and sedimentation interaction parameters for measuring the second virial coefficient and their utility as predictors of protein aggregation, Biophys. J. 99 (2010) 2657-2665.

[83] J.V. Schaefer, A. Plückthun, Engineering aggregation resistance in IgG by two independent mechanisms: lessons from comparison of Pichia pastoris and mammalian cell expression, J. Mol. Biol. 417 (2012) 309-335.

[84] F.X. Schmid, Biological Macromolecules: UV-Visible Spectrophotometry, eLS 2001.

[85] P. Simeonov, R. Berger-Hoffmann, R. Hoffmann, N. Straeter, T. Zuchner Surface supercharged human enteropeptidase light chain shows improved solubility and refolding yield, Protein Eng. Des. Sel. 24 (2011) 261-268.

[86] M. Stefani, C. Dobson, Protein aggregation and aggregate toxicity: new insights into protein folding, misfolding diseases and biological evolution, J Mol. Med. 81 (2003) 678-699.

[87] P.H. Tan, V. Chu, J.E. Stray, D.K. Hamlin, D. Pettit, D.S. Wilbur, R.L. Vessella, P.S. Stayton, Engineering the isoelectric point of a renal cell carcinoma targeting antibody greatly enhances scFv solubility, Immunotechnology 4(1998)107-114.

[88] X. Tian, A.E. Langkilde, M. Thorolfsson, H.B. Rasmussen, B. Vestergaard, Smallangle X-ray scattering screening complements conventional biophysica analysis: comparative structural and biophysical analysis of monoclonal antibodies IgG1, IgG2, and IgG4, J. Pharm. Sci. 103 (2014) 1701-1710.

[89] S.R. Trevino, J.M. Scholtz, C.N. Pace, Amino acid contribution to protein solubility: Asp, Glu, and Ser contribute more favorably than the other hydrophilic amino acids in RNase Sa, J. Mol. Biol. 366 (2007) 449-460.

[90] A. Trovato, F. Seno, S.C.E. Tosatto, The PASTA server for protein aggregation prediction, Protein Eng. Des. Selec. 20 (2007) 521-523.

[91] G. Walsh, Biopharmaceutical benchmarks 2010, Nat. Biotechnol. 28 (2010) 917-924.

[92] G. Walsh, Biopharmaceutical benchmarks 2014, Nat. Biotechnol. 32 (2014) 992-1000.

[93] X.L. Wang, T.K. Das, S.K. Singh, S. Kumar, Potential aggregation prone regions in biotherapeutics A survey of commercial monoclonal antibodies, MABS 1 (2009) 254-267.

[94] Y. Wang, R.F. Latypov, A. Lomakin, J.A. Meyer, B.A. Kerwin, S. Vunnum, G.B. Benedek, Quantitative evaluation of colloidal stability of antibody solutions using PEG-induced liquid-liquid phase separation, Mol. Pharm. 11 (2014) 1391-1402.

[95] J. Warwicker, S. Charonis, R.A. Curtis, Lysine and arginine content of proteins: computational analysis suggests a new tool for solubility design, Mol. Pharm. 11 (2014) 294-303.

[96] W.F. Weiss, T.K. Hodgdon, E.W. Kaler, A.M. Lenhoff, C.J. Roberts, Nonnative protein polymers: structure, morphology, and relation to nucleation and growth, Biophys. J. 93 (2007) 4392-4403.

[97] W.F.I.V. Weiss, T.M. Young, C.J. Roberts, Principles, approaches, and challenges for predicting protein aggregation rates and shelf life, J. Pharm. Sci. 98 (2009) 1246-1277.

[98] A. Wörn, A. Plückthun, Different equilibrium stability behavior of scFv fragments: identification, classification, and improvement by protein engineering, Biochemistry 38 (1999) 8739-8750.

[99] S. Yadav, T.M. Laue, D.S. Kalonia, S.N. Singh, S.J. Shire, The influence of charge distribution on self-association and viscosity behavior of monoclonal antibody solutions, Mol. Pharm. 9 (2012) 791-802.

[100] S. Yagi, S. Akanuma, A. Yamagishi, Addition of negatively charged residues can reverse the decrease in the solubility of an acidic protein caused by an artificially introduced non-polar surface patch, Biochim. Biophys. Acta Proteins Proteomics 1844 (2014) 553-560. 